\title{
Molecular regionalization in the compact brain of the meiofaunal annelid Dinophilus gyrociliatus (Dinophilidae)
}

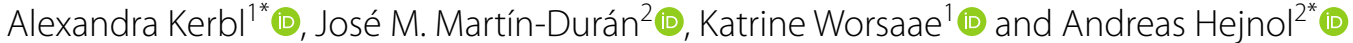

\begin{abstract}
Background: Annelida is a morphologically diverse animal group that exhibits a remarkable variety in nervous system architecture (e.g., number and location of longitudinal cords, architecture of the brain). Despite this heterogeneity of neural arrangements, the molecular profiles related to central nervous system patterning seem to be conserved even between distantly related annelids. In particular, comparative molecular studies on brain and anterior neural region patterning genes have focused so far mainly on indirect-developing macrofaunal taxa. Therefore, analyses on microscopic, direct-developing annelids are important to attain a general picture of the evolutionary events underlying the vast diversity of annelid neuroanatomy.

Results: We have analyzed the expression domains of 11 evolutionarily conserved genes involved in brain and anterior neural patterning in adult females of the direct-developing meiofaunal annelid Dinophilus gyrociliatus. The small, compact brain shows expression of dimmed, foxg, goosecoid, homeobrain, nk2.1, orthodenticle, orthopedia, pax6, six3/6 and synaptotagmin-1. Although most of the studied markers localize to specific brain areas, the genes six3/6 and synaptotagmin-1 are expressed in nearly all perikarya of the brain. All genes except for goosecoid, pax 6 and $n k 2.2$ overlap in the anterior brain region, while the respective expression domains are more separated in the posterior brain.

Conclusions: Our findings reveal that the expression patterns of the genes foxg, orthodenticle, orthopedia and six3/6 correlate with those described in Platynereis dumerilii larvae, and homeobrain, nk2.1, orthodenticle and synaptotagmin-1 resemble the pattern of late larvae of Capitella teleta. Although data on other annelids are limited, molecular similarities between adult Dinophilus and larval Platynereis and Capitella suggest an overall conservation of molecular mechanisms patterning the anterior neural regions, independent from developmental and ecological strategies, or of the size and configuration of the nervous system.
\end{abstract}

Keywords: Meiofauna, Direct development, Brain, Nervous system, Annelida, Larva, Animal evolution

\section{Background}

Several detailed studies on the nervous systems of various groups within Annelida ("segmented worms") demonstrate that this organ system displays a remarkable variability in arrangement and structure of the brain and neuropil, number of ventral nerve cords and nerves, as well as layout of the stomatogastric nervous system

\footnotetext{
*Correspondence: alexandra.kerbl@bio.ku.dk; andreas.hejnol@uib.no ${ }^{1}$ Marine Biology Section, Department of Biology, Faculty of Science, University of Copenhagen, Universitetsparken 4, 2100 Copenhagen, Denmark

2 Sars International Centre for Marine Molecular Biology, University of Bergen, Thormøhlensgate, 55, 5006 Bergen, Norway
}

and peripheral nerves (e.g., [18]). The position and configuration of the brain vary among annelids, most commonly consisting of a subepidermal dorsal neuropil with peripheral perikarya, subdivided into discrete clusters or lobes $[1,5,6,9,10]$, but occasionally situated intraepidermally (e.g., [11, 12]) and ventrally (e.g., [13-15]), or anteriorly [13], or having a uniform compact morphology without apparent compartmentalization $[11,12$, 16-26]. Despite this morphological diversity, the underlying molecular patterns of neural-related genes that are evolutionarily conserved in Protostomia (e.g., Mollusca, Platyhelminthes, Nemertea, Nematoda, Arthropoda and Brachiopoda [16-26]) and Deuterostomia (e.g., 
Hemichordata and Chordata, e.g., [9, 27-30]) have been analyzed only in a handful of annelid taxa [23, 31-35]. For instance, the transcription factor six3/6 and the gene synaptotagmin-1 (coding for the eponymous membrane-trafficking protein) pattern the presumptive neuroectoderm and the larval brain in Platynereis dumerilii and Capitella teleta [23, 33, 34], while domains of the genes foxg and orthodenticle appear in close proximity to the locomotory cilia of the prototroch (see Table 1 for comparison [21-23, 36]). However, most of the annelid species investigated with regard to molecular patterning of the anterior neural region so far (e.g., C. teleta and $P$. dumerilii) are characterized by exhibiting an indirect development comprising a planktonic microscopic larva and a macroscopic adult [16, 22, 23, 37-40]. Information about these patterning mechanisms in Oligochaeta and Hirudinea is still limited (e.g., [35, 41-44], Table 1 and literature therein) and completely absent in direct-developing, microscopic interstitial groups such as Dinophilidae [45-48]. Neuroanatomical studies of developing and adult brains in these microscopic species are also very limited (e.g., [13, 45, 46, 49-51]). Therefore, investigations in members of annelid lineages with alternative life cycles, ecological strategies and neuroanatomies are essential to attain a better understanding of the diversification of the nervous system in Annelida (and Spiralia) and its underlying molecular patterning [52, 53].

Dinophilidae is a species-poor meiofaunal group, whose members occupy interstitial habitats and lives in the crevices of sandy sediment or in biofilms on macroalgae in tidal marine regions [54-56]. It comprises two clades, Dinophilus and Trilobodrilus, whose representatives share their diminutive body size and being only few segments long pseudocoelomates with protonephridia, lacking chaetae, parapodia and appendages, but having a dense ventral ciliary field and direct development [45, 57-59]. Within Dinophilus, two morphotypes can be distinguished: one strongly pigmented, monomorphic group with prolonged life cycle and encystment period $[55,60]$ and a smaller, transparent, strongly dimorphic group with rapid life cycle $[58,61,62]$. The latter is represented by $D$. gyrociliatus, whose females (Fig. 1a) resemble the adults of the other morphotype to a certain degree, while the males are extremely miniaturized and short lived [61, 63, 64]. The brain of Dinophilus gyrociliatus consists of a compact neuropil formed by a dense meshwork of nerve fibers (Fig. 1b, c, e-g) with condensed fiber bundles probably representing commissures surrounded by a dense layer of perikarya (Fig. 1d, [45, 46]). The circumesophageal connective, which links the dorsal brain to the ventral nerve cords, bifurcates anteriorly at approximately the middle of the mouth opening into a ventral and a dorsal component (Fig. 1e). The ventral branch is connected to the stomatogastric nerve ring (a nervous loop dorsally lining the esophagus) and also gives rise to several nerve fibers innervating anterior compound cilia and at least the ventral pair of compound cilia at the anterior tip of the prostomium $[2,45,46]$. The dorsal branch gives rise to the paired dorsal, dorsolateral and lateral peripheral longitudinal nerves and the nerves innervating the nuchal organs $[45,46]$. Approximately 750 densely packed, uniform perikarya surround the neuropil on the anterior, lateral, dorsal and posterior sides and very weak on the ventral side (Fig. 1d). The entire brain is located closely adjacent to the dorsal epidermis [45]. The eyes are sunken into the layer of brain perikarya (Fig. 1d) and seemingly directly connected to the neuropil without the formation of optic tracts $[45,58]$. Since its nervous system and development are morphologically mapped in high detail $[45,46,50,58,63,64], D$. gyrociliatus emerges as a suitable meiofaunal candidate next to the already established annelid models $P$. dumerilii and C. teleta.

In this study, we characterize the expression pattern of 11 genes with a putatively evolutionarily conserved role in patterning anterior neural regions in the brain of adult females of the microscopic $D$. gyrociliatus. These genes are generally associated with the anterior neurogenic domain (e.g., six3/6, orthopedia, synaptotagmin-1), ciliary bands (foxg) and sensory organs (pax6), or play a putative role in neurosecretory cell differentiation (dimmed) in previously investigated annelid and other invertebrate species (Table 1 and literature therein). We thus aim to investigate the possibility of a common molecular regionalization of the annelid brain, despite interspecific differences in the number of cells and morphological complexity, and provide a protocol for in situ hybridization approaches for adults in this microscopic annelid species.

\section{Methods \\ Specimen rearing and fixation}

Adult specimens of Dinophilus gyrociliatus Schmidt, 1848 , are kept in culture in plastic boxes with seawater (28 per mille salinity) at $18{ }^{\circ} \mathrm{C}$ in the dark; water was exchanged twice per month. Spinach and fish food (Tetramin flakes for aquarium fish) were added to the cultures every 14 days (protocol modified from [65]). Mature animals were separated from the main cultures in small petri dishes and starved for 24-96 h. The specimens were fixed with $4 \%$ paraformaldehyde in phosphate-buffered saline (PBS, $\mathrm{pH}$ 7.4) for one hour at room temperature directly after anesthetization with isotonic $\mathrm{MgCl}_{2}$. The fixative was removed by several rinses in $0.1 \% \mathrm{PTw}$ (PBS $+0.1 \%$ Tween-20) before storing the specimens in $100 \%$ methanol at $-20{ }^{\circ} \mathrm{C}$ for later use. 


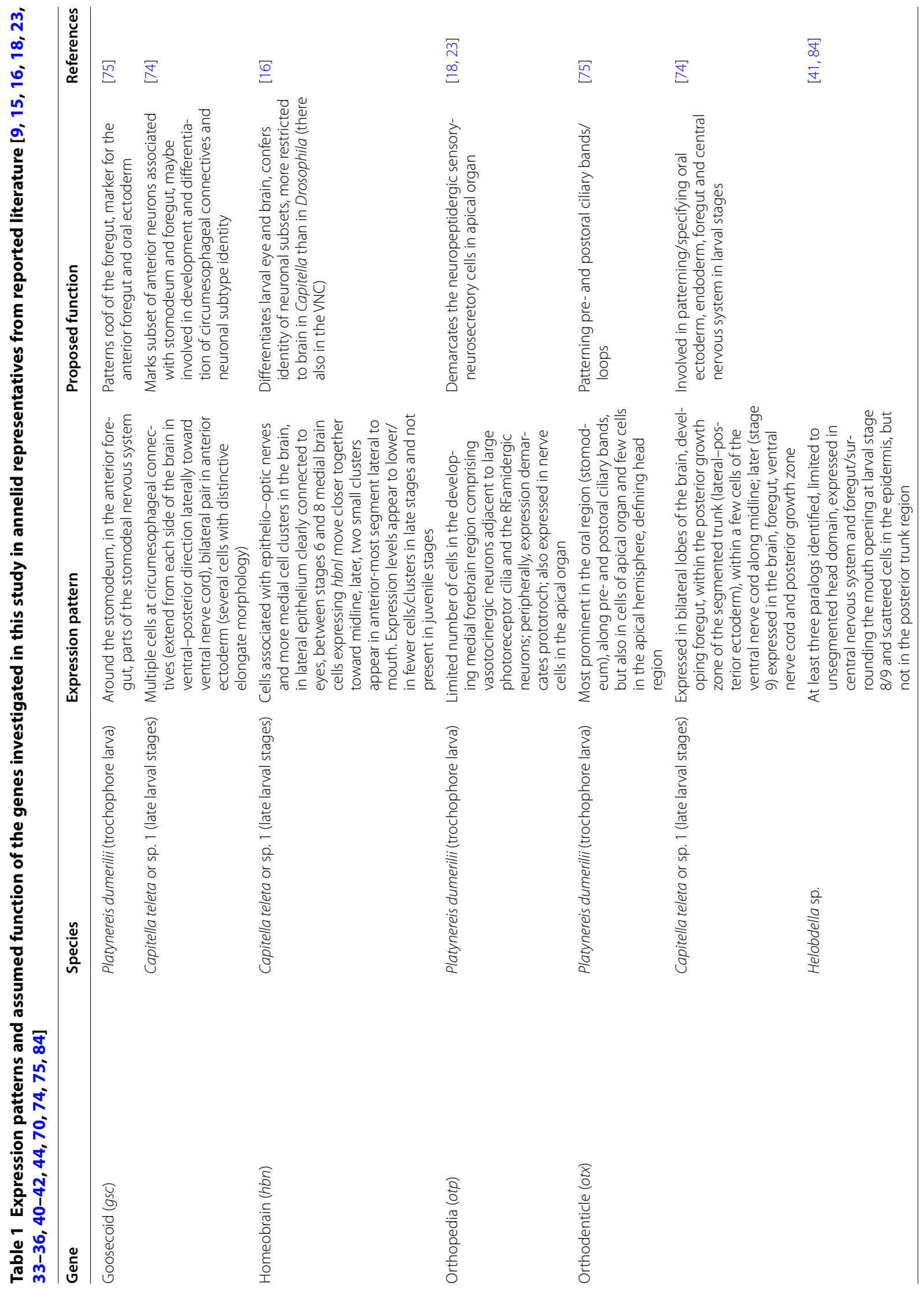




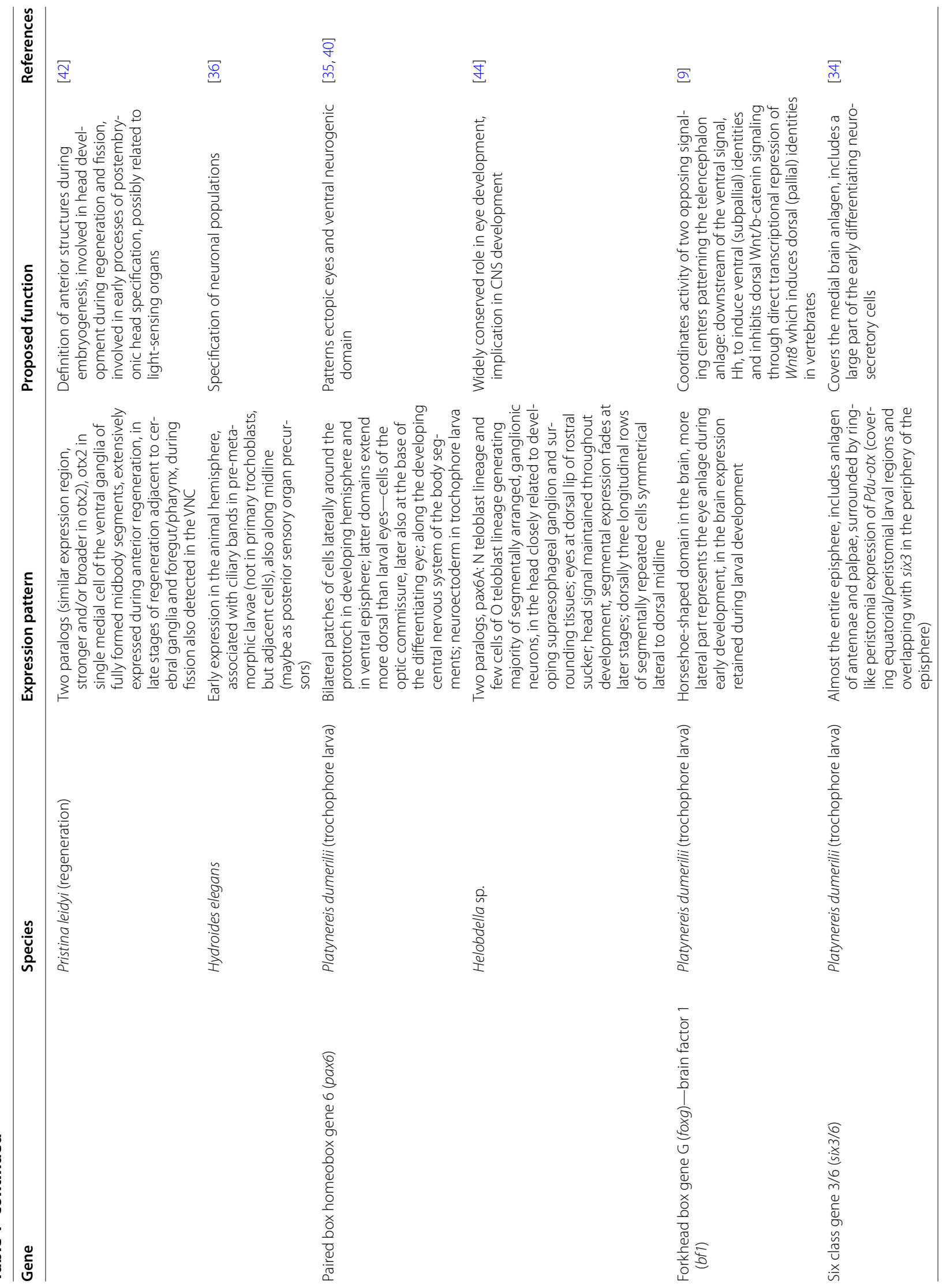




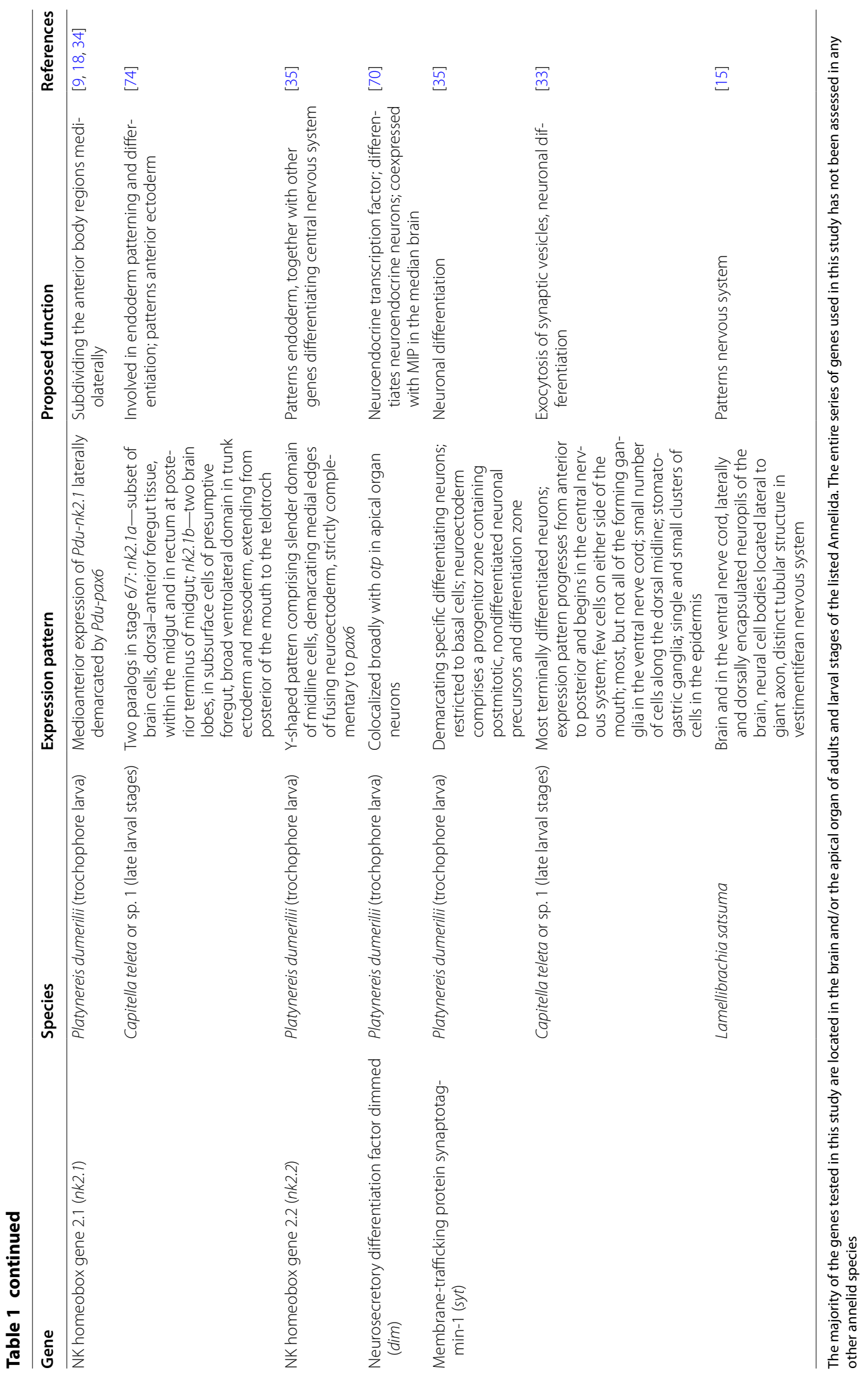




\section{Gene cloning and orthology assignment}

Putative orthologs of the genes of interest (dimmed, foxg, goosecoid, homeobrain, $n k 2.1, n k 2.2$, orthodenticle, orthopedia, pax6, six3/6, synaptotagmin-1) were identified by BLAST searches in the transcriptome of D. gyrociliatus using known sequences from other species as query. $D$. gyrociliatus transcriptome was constructed from approximately 300 specimens of mixed sexes and life stages, sequenced with Illumina technology and assembled with Trinity v.r20140717 using default settings [66]. The raw reads have been deposited at SRA: SRA Experiment: SRX2030658. The orthology of the genes was assigned by Bayesian phylogenetic analyses: amino acid sequences of D. gyrociliatus genes (GenBank Accession Numbers KX555473-KX555483) and orthologous proteins from other animals (Additional file 1, [22]) were aligned with MUSCLE [67], and the Bayesian phylogenetic analyses were performed on each dataset using MrBayes 3.2.6 [68], with settings described in [22]. Each analysis was run for 30,000,000 generations in four runs. A consensus tree and posterior probabilities for each branch were calculated and visualized in FigTree (http://tree. bio.ed.ac.uk/software/figtree/). Tracer (http://tree.bio. ed.ac.uk/software/tracer/) was used to test whether the trees of the four runs converged. A pair of gene-specific primers (Additional file 2) was designed for each gene to clone full-length fragments of each of the candidate genes (ranging between 700 and $1400 \mathrm{bp}$, Additional file 1) except for $D g-g s c$ (partial transcript). The cDNA library used was created using a SuperScript ${ }^{\mathrm{TM}}$ III FirstStrand Synthesis System for RT-PCR kit following RNA extraction with a RiboPure ${ }^{\mathrm{TM}}$ Kit and approximately 300 animals (mixed stages and sexes, but mainly adult females). The transcripts were subsequently used to synthesize antisense digoxigenin-labeled RNA probes using an Ambion MEGAscript T7/SP6 Transcription Kit in combination with a TaKaRa RNA in vitro transcription kit. Preliminary studies with antisense and sense probes of other genes indicated a high specificity of the probes (data not shown).

\section{Whole-mount in situ hybridization (modified from [69])}

Fixed, adult female D. gyrociliatus were permeabilized with proteinase $\mathrm{K}(0.005 \mathrm{mg} / \mathrm{ml}$ in PTw for $10 \mathrm{~min}$ at room temperature) and subsequently treated with glycine $(2 \mathrm{mg} / \mathrm{ml})$ and triethanolamine (TEA, $0.1 \mathrm{M} \mathrm{pH}$ 7.6; $2 \times 5 \mathrm{~min}$; after the first change adding $3 \mu \mathrm{l} / \mathrm{ml}$ acetic anhydride, after five minutes another $6 \mu \mathrm{l} / \mathrm{ml}$ acetic anhydride without changing the TEA solution) to block positive charges. Following washes with $0.1 \%$ PTw, specimens were postfixed in $3.7 \%$ formaldehyde in $0.1 \% \mathrm{PTw}$ for $60 \mathrm{~min}$ at room temperature, followed by several washes in $0.1 \% \mathrm{PTw}$ ( 5 min each) prior to pre-hybridization and hybridization. These steps were carried out at $62{ }^{\circ} \mathrm{C}$ in a hybridization oven. Antisense digoxigenin-labeled riboprobes were diluted to a final concentration of $1 \mathrm{ng} / \mu \mathrm{l}$ in hybridization solution. After hybridization (for $12-36 \mathrm{~h}$ at $62{ }^{\circ} \mathrm{C}$ ), probes were recovered and samples were washed at hybridization temperature with graded series of Hybe buffer to SSC and following to $0.1 \%$ PTw and $0.1 \%$ PBT (PBS $+0.1 \%$ Triton $\mathrm{X}-100+0.1 \%$ BSA (bovine serum albumin)). After two washes in maleic buffer (MAB; $100 \mathrm{mM}$ maleic acid, $150 \mathrm{mM} \mathrm{NaCl}, 0.1 \%$ Tween-20, $\mathrm{pH}$ to 7.5 with $\mathrm{NaOH}$ ) at room temperature, specimens were blocked for $1 \mathrm{~h}$ at room temperature in blocking solution (1\% blocking reagent (Roche)). Antidigoxigenin AP-conjugated antibody (Roche) at a final 1:5000 dilution in blocking solution was incubated overnight at $4{ }^{\circ} \mathrm{C}$. After several washes on $0.1 \%$ PBT followed by $0.1 \%$ PTw at room temperature, samples were transferred to AP buffer and developed with 5-bromo-4-chloro-3-indolyl phosphate 4 toluidine salt (BCIP) and 4-nitro blue tetrazolium (NBT) until the signal was visible. The reaction was stopped in AP buffer without $\mathrm{MgCl}_{2}$. Specimens were stored in $70 \%$ glycerol in $0.1 \% \mathrm{PTw}$ at $4{ }^{\circ} \mathrm{C}$ until further examination.

\section{Immunohistochemistry after whole-mount in situ hybridization}

After the in situ hybridization protocol, adult females of D. gyrociliatus were transferred to $0.1 \% \mathrm{PTw}$ prior to pre-incubation with $1 \%$ PTA (PBS $+1 \%$ Triton X-100, $0.05 \% \mathrm{NaN}_{3}, 0.25 \% \mathrm{BSA}$ and $5 \%$ sucrose). Afterward, samples were incubated for up to $24 \mathrm{~h}$ at $\mathrm{RT}$ in the primary antibodies monoclonal mouse anti-acetylated $\alpha$-tubulin in a final concentration of 1:400 in $1 \%$ PBT. Sample specimens for a better description of the nervous system (Fig. 1) were also incubated with polyclonal rabbit anti-serotonin and anti-FMRFamide in a final concentration of 1:200. After several washes in PBS and $1 \%$ PBT, specimens were incubated with the appropriate secondary antibodies conjugated with fluorophores (goat antimouse labeled with CY5, goat antirabbit labeled with TRITC; in a final concentration of 1:400) for up to $48 \mathrm{~h}$ at RT. Thereafter, specimens were washed several times in PBS and mounted in fluoromount with DAPI.

\section{Imaging}

The specimens were mounted in $70 \%$ glycerol in $0.1 \%$ PTw or in Vectashield with DAPI. Images of wholemount specimens with NBT/BCIP precipitation were taken using a Zeiss Axio Imager 2 Microscope, with mounted Zeiss Axiocam MRc5 camera and the software package Zeiss ZEN 2 or an Olympus IX 70 and a mounted Olympus DP73 microscope camera in combination with the software cellSens (Figs. 2, 3, 4). 


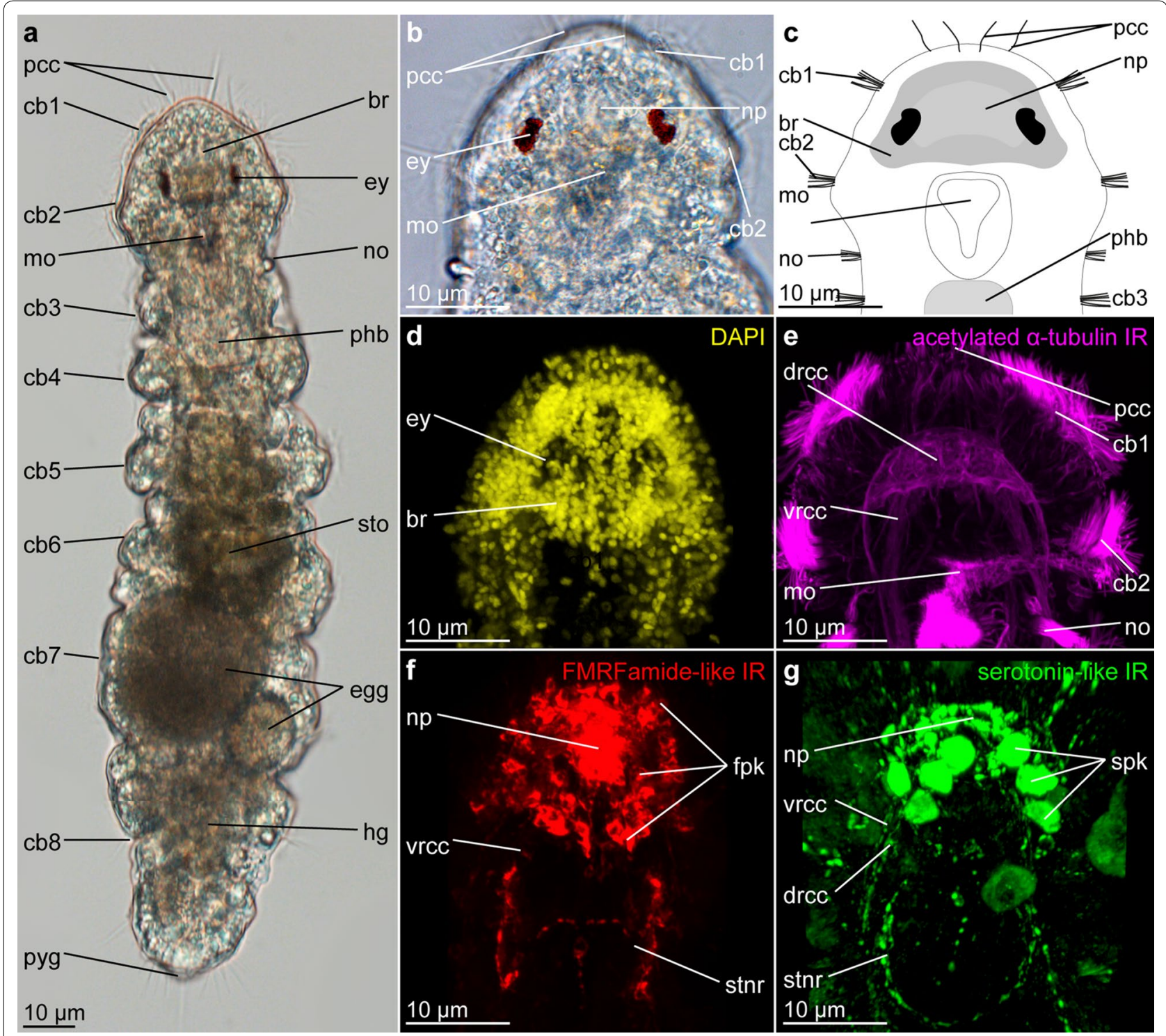

Fig. 1 Morphology of the nervous system of adult female Dinophilus gyrociliatus. Light microscopic images of the adult female (a) and a detail of the head $(\mathbf{b})$, which was subsequently used to create the template to map the gene expression patterns on $\mathbf{c}$. $\mathbf{d}-\mathbf{g}$ Details of the brain visualized by immunohistochemical labeling and confocal laser scanning microscopy of the direct labeling of DNA in the nuclei with DAPI (d), and the indirect labeling of acetylated a-tubulin-like immunoreactivity (e), FMRFamide-like immunoreactivity (f) and serotonin-like immunoreactivity $(\mathbf{g})$. br brain, cb1-8 ciliary bands 1-8, drcc dorsal root of the circumesophageal connective, egg eggs, ey eye, fpk perikarya with FMRFamide-like immunoreactivity, mo mouth opening, no nuchal organ, $n p$ neuropil, pcc prostomial compound cilia, phb pharyngeal bulb, pyg pygidium, spk perikarya with serotonin-like immunoreactivity, stnr stomatogastric nerve ring, sto stomach, vrcc ventral root of the circumesophageal connective

Immunohistochemically treated samples (Figs. 1, 5, 6, 7) were examined using an Olympus IX 81 inverted microscope with a Fluoview FV-1000 confocal unit. Acquired z-stacks were exported to the Imaris 7.0 software package to conduct further three-dimensional investigations and prepare representative images. Brightness and contrast were adjusted in Adobe Photoshop CC 2015 and plates assembled in Adobe Illustrator CC 2015. The latter also was used to create the schematic drawings.

\section{Results}

Gene identification and orthology analyses

To gain a better understanding of the molecular regionalization of the brain of the adult female D. gyrociliatus, we isolated the transcription factors dimmed (dim), foxg, goosecoid (gsc), homeobrain (hbn), nk2.1, nk2.2, orthodenticle (otx), orthopedia (otp), pax6 and six3/6, as well as the membrane-trafficking protein synaptotagmin-1 (syt) by gene-specific PCR (Additional file 1). We performed 
Bayesian analysis to confirm their orthology (Additional files $1,3,4,5,6,7,8)$ and referred to D. gyrociliatus orthologous genes as $D g$-dim, $D g$-foxg, $D g-g s c, D g-h b n$, Dg-nk2.1, Dg-nk2.2, Dg-otx, Dg-otp, Dg-pax6, Dg-six3/6 and $D g$-syt.

\section{Expression of the neural PRD class genes $D g-g s c, D g-h b n$, Dg-otp, Dg-otx and Dg-pax6}

The transcription factor goosecoid (Dg-gsc) was expressed in a narrow region in the posteroventral brain (Fig. 2a-e) and between this region and the anterior region of the pharyngeal epithelium (Figs. 2a-c, 6d, e, 8b, c). Additionally, four distinct cells (or small groups of cells) were labeled anteriorly to this broad domain in the brain (Figs. 2a-c, 8c). Reflective microscopy further suggested that this gene is also expressed lateral in the prostomium, adjacent to the second ciliary band, where these domains extend further ventrally and dorsally than the expression region of the brain (Figs. 6d, e, 8b).

The gene homeobrain $(D g-h b n)$ showed a much weaker expression in the anterodorsal region of the brain (Figs. 2d-f, 6f, g, 8b, c) and two lateral spots with stronger expression, where the ventral root of the circumesophageal connective extends posteriorly from the neuropil and brain (Figs. 2d, f, 7f, g, 8a).

The transcription factor orthopedia (Dg-otp) had a very narrow expression pattern (Figs. 2g, i, 7h, i, 8a-c), which consisted of a strongly labeled spot in the anteroventral region of the brain (Figs. $2 \mathrm{~g}-\mathrm{i}, 7 \mathrm{i}, 8 \mathrm{~b}, \mathrm{c}$ ), between the nerves extending to the prostomial compound cilia, and a pair of less prominent, but more extended patches ventral to the eyes, dorsal to the neuropil (Figs. 2g-i, 7h, i, 8a). This pattern superficially resembled the one found with orthodenticle (Dg-otx). However, Dg-otx was expressed more ventrally in the posterior part of the brain (Figs. $2 j-$ $1,6 i, 8 b, c)$, in one pair of patches at the base of the ventral root of the circumesophageal connective (Figs. 2j-l, $6 \mathrm{i}, 8 \mathrm{~b})$. The anterior expression pattern of $D g$-otx resembles the anterior domain of $D g-h b n$, although it is located more ventrally and was weaker than the other studied domains (Figs. 2j-1, 6i, 8c).
Finally, the gene pax6 (Dg-pax6) was detected in one pair of lateral elongated domains, roughly ventral to the eyes (Figs. 2m, o, 7j, k, 8a). However, the expression was deeper within the brain and not only on the dorsal surface, where the eyes locate (Figs. 2n, o, 7j).

\section{Expression of the Fox class gene $D g$-foxg}

The forkhead transcription factor $G$ (Dg-foxg) was expressed in one pair of strongly labeled posteromedial patches close to the ventral root of the circumesophageal connective (Figs. 3a-c, 7d, e, 8a). Additionally, a series of small dot-like patches formed a sickle-shaped, narrow line in the anteromedian region of the brain, approximately spanning between the nerves innervating the anterior prostomial ciliary band (Figs. 3a-c, 7d, e).

\section{Expression of the six class gene $D g$-six $3 / 6$}

The six class gene six3/6 (Dg-six3/6) had a rather broad expression pattern (Figs. 3d-f, 5f, g, 8a-c) when compared to the genes described above (Figs. 2, 6, 7, 8a-c). $D g$-six3/6 showed a nearly continuous dorsoventral pattern anterior and posterior to the neuropil, which was connected by strongly labeled lateral regions, forming a dorsolateral clasp around the neuropil (Figs. 3e, f, 5f, g, $8 \mathrm{a}-\mathrm{c})$. On the ventral side, only the transverse patches anterior and posterior to the neuropil were detected (Figs. 3d, f, 5g). Additionally, a pair of elongated, beanshaped expression domains localized at the anterolateral edge of the mouth (Figs. 3d, f, 5f, g, 8c).

\section{Expression of the neurosecretory differentiation factor Dg-dim}

The gene dimmed is a neurosecretory differentiation factor present in the apical organ of P. dumerilii [70] and in specific neural populations in the brain and ventral nerve cord in the larvae and adult of D. melanogaster [71-73]. In adult $D$. gyrociliatus females, $D g$-dim showed a mainly dorsal pattern in the brain, which is broad in the anterior and posterior region of the brain, but more narrow on the dorsal side than, e.g., the domains formed by $D g$ six3/6 (Figs. 3g-i, 5d, e).

\footnotetext{
(See figure on next page.)

Fig. 2 Expression pattern of paired class genes Dg-gsc $(\mathbf{a}-\mathbf{c})$, Dg-hbn $(\mathbf{d}-\mathbf{f}), D g$-otp $(\mathbf{g}-\mathbf{i})$, Dg-otx $(\mathbf{j}-\mathbf{I})$ and Dg-pax6 ( $\mathbf{m}-\mathbf{o})$ in adult females of Dinophilus gyrociliatus. The expression pattern of the respective gene is shown in ventral $(\mathbf{a}, \mathbf{d}, \mathbf{g}, \mathbf{j}, \mathbf{m}$ ) and lateral (ventral side to the left, $\mathbf{b}, \mathbf{e}, \mathbf{h}, \mathbf{k}, \mathbf{n})$ views as well as in schematic drawings in ventral view $(\mathrm{c}, \mathrm{f}, \mathrm{i}, \mathrm{l}, \mathrm{o})$. Dg-gsc is expressed in the posteroventral region of the brain, the anterior pharyngeal epithelium and two small cell populations close to the second prostomial ciliary band (a-c). Dg-hbn shows a spot-like expression, though the individual patches are linked to form a continuous band in the anterior region and two separate posteroventral spots (d-f). Dg-otp ( $(\mathbf{g}$-i) and Dg-otx $(\mathbf{j}-\mathbf{I})$ are also expressed in the anterior and posterior region of the brain: Dg-otp shows a narrow region of expression in the anterior region of the brain $(\mathbf{g}-\mathbf{i})$, while the posterior spots are more clearly demarcated in Dg-otx $(\mathbf{j}-\mathbf{I})$. Dg-pax6 is found to not only pattern the area of the eyes, but also extend further along the brain surface as well as into the brain $(\mathbf{m}-\mathbf{-})$. br brain, cbg ciliary band gland, ey eye, fg frontal gland, mo mouth opening, $n p$ neuropil, pcb prostomial ciliary band, phb pharyngeal bulb, vrcc ventral root of the circumesophageal connective
} 

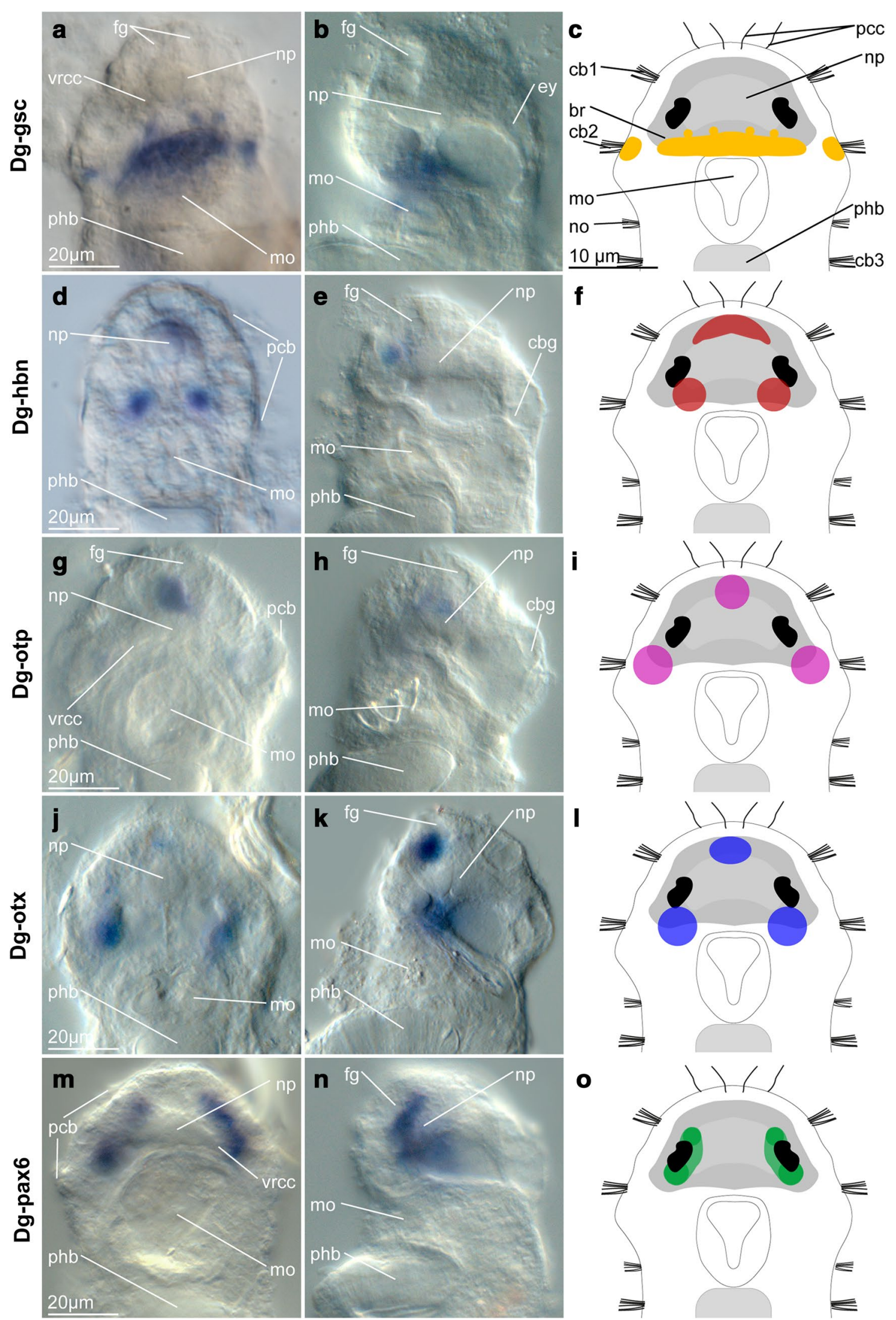

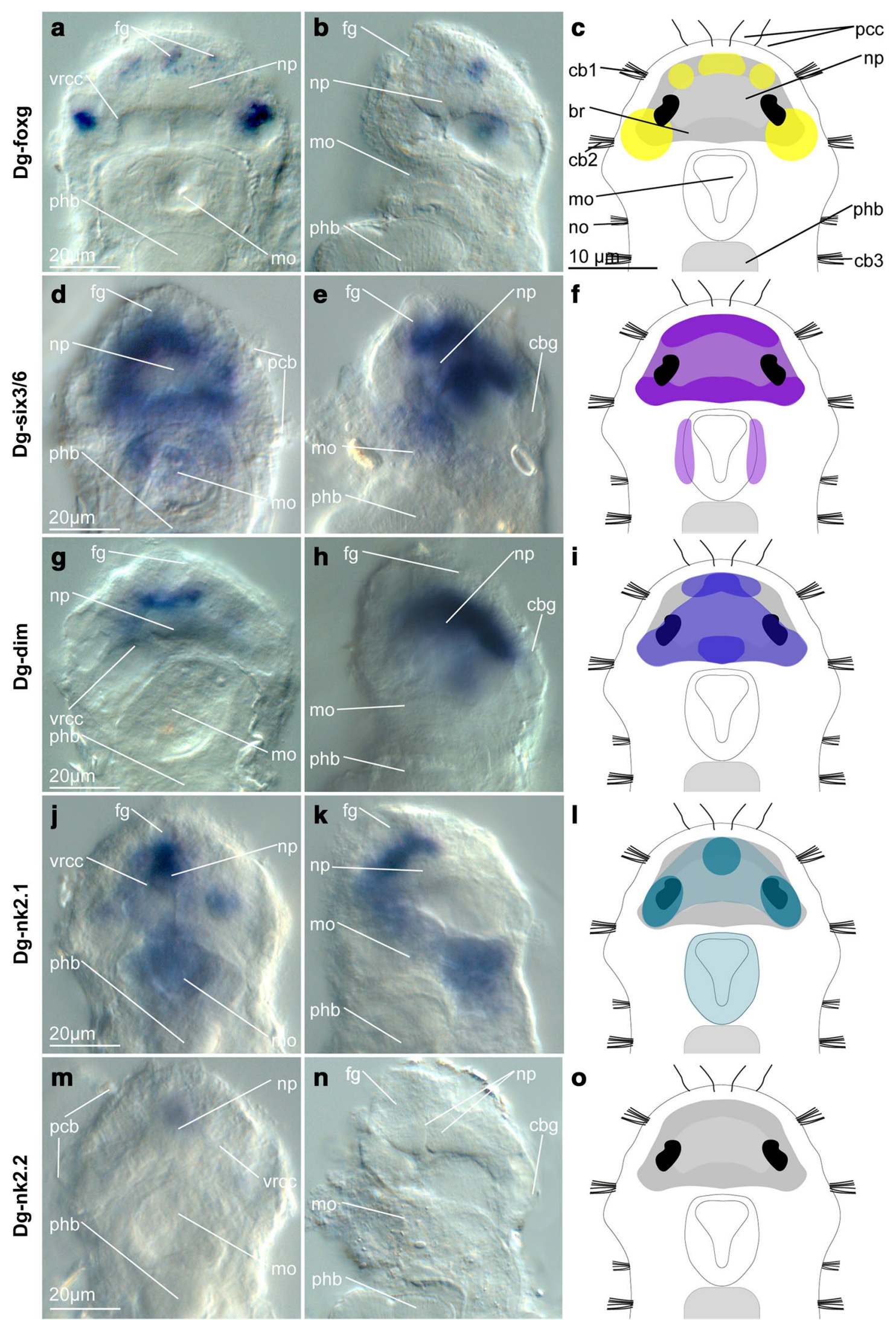
(See figure on previous page.)

Fig. 3 Expression pattern of fox gene $D g$-foxg $(\mathbf{a}-\mathbf{c})$, six class gene $D g$-six3/6 (d-f), neuropeptidergic differentiation factor Dg-dim $(\mathbf{g}-\mathbf{i})$ and NK homeobox genes $D g-n k 2.1(\mathbf{j}-\mathbf{I})$ and $D g-n k 2.2(\mathbf{m}-\mathbf{o})$ in adult female Dinophilus gyrociliatus. The expression pattern of the respective gene is shown in ventral $(\mathbf{a}, \mathbf{d}, \mathbf{g}, \mathbf{j}, \mathbf{m})$ and lateral (ventral side to the left, $\mathbf{b}, \mathbf{e}, \mathbf{h}, \mathbf{k}, \mathbf{n})$ views as well as in schematic drawings in ventral view $(c, f, i, l, o)$. Dg-foxg resembles the pattern of $\mathrm{Dg}$-hbn, but shows more prominent labeling in the anteromedian region and the posterolateral patches, which are shifted anterior to the centers of $D g$-hbn (a-c). Dg-six3/6 labels cells in the entire brain though the ventral side shows gaps between the anterior and posterior continuous patches. Additionally, the anterolateral ectodermal regions of the mouth and pharynx are labeled (d-f). Dg-dim shows a complex pattern with a dorsomedian expression, which bifurcates ventrally in the anterior and posterior region, forming a clasp embracing the neuropil $(\mathbf{g}-\mathbf{i})$. Dg-nk2.1 is expressed strongest in the anterior region of the brain and only weakly in the posterior part. However, Dg-nk2.1 also labels the foregut in adult females (j-I) as well as the hindgut, which is complemented by Dg-nk2.2, which does not label the brain (m-o), but the midgut. br brain, cbg ciliary band gland, fg frontal gland, mo mouth opening, $n p$ neuropil, $p c b$ prostomial ciliary band, phb pharyngeal bulb, vrcc ventral root of the circumesophageal connective

\section{Expression of the NK homeobox genes Dg-nk2.1 and Dg-nk2.2}

Different to other brain markers, such as $D g$-six3/6 and $D g$-dim, the transcription factor $D g-n k 2.1$ exhibited a stronger expression on the anteroventral and posterodorsal side of the neuropil (Figs. 3j-l, 7f, g, 8b, c). Additionally, a pair of spot-like domains was located laterally to the eyes and medioventrally to the neuropil (Figs. 3j, l. $7 \mathrm{~g}$ ). The three anterior patches (ventromedian and mediolateral) were connected by a broader domain ventral to the neuropil (Figs. 3j-l, 7f, g, 8a, b). The dorsal region of the brain did not show any additional labeling with $D g$ $n k 2.1$ (Figs. 3j-l, 7g, 8a). Additionally, $D g-n k 2.1$ is also expressed in the pharyngeal epithelium (Figs. 3j-l, 7f). We did not detect any expression of $D g-n k 2.2$ in the brain (Fig. 3m-o), but in the mid- and hindgut (Additional file 9).

\section{Expression of $D g$-syt}

The gene synaptotagmin-1 (Dg-syt) got recognized recently as a broad nervous system marker [33]. In accordance with other annelids such as C. teleta [33]
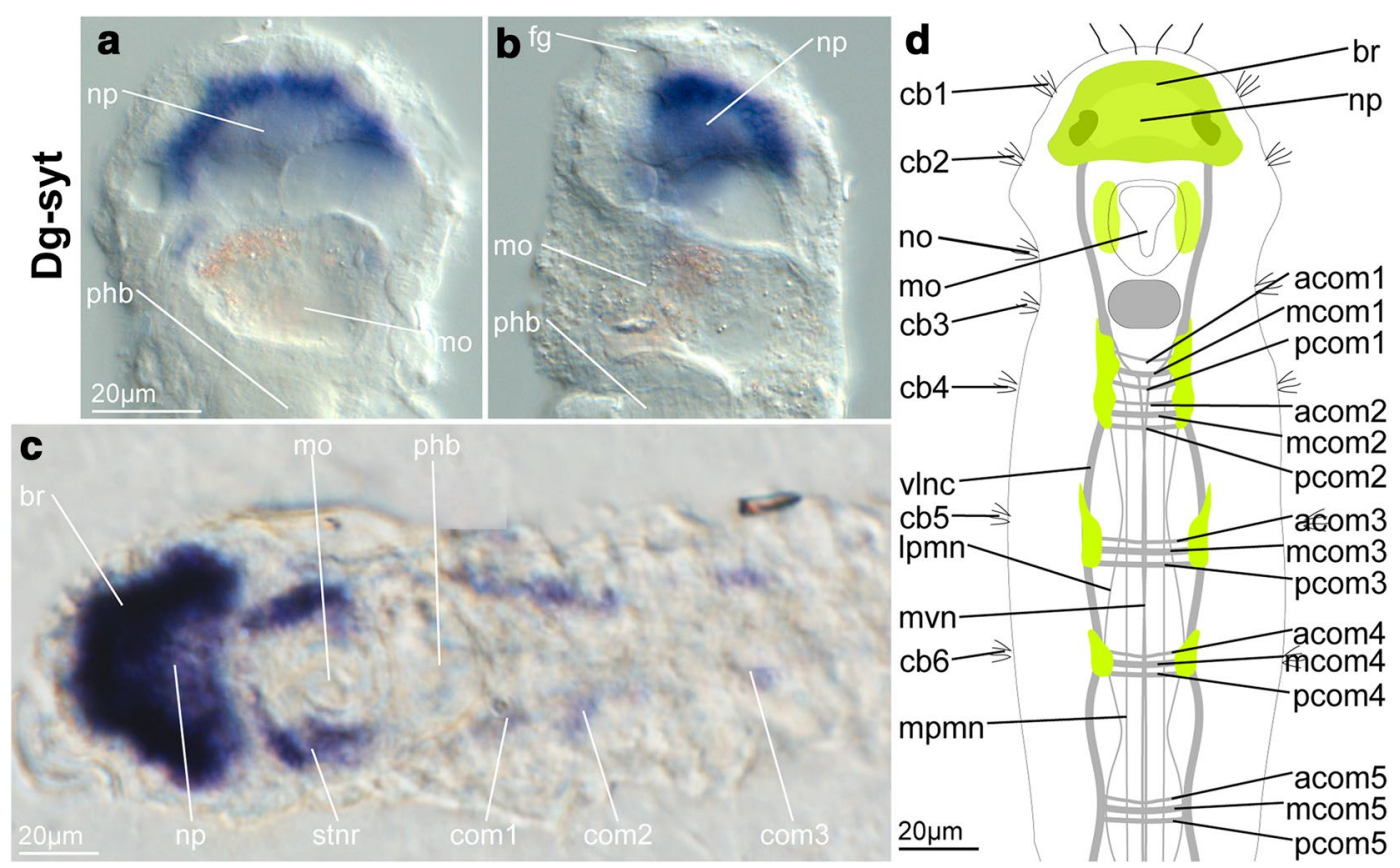

Fig. 4 Expression pattern of the membrane-trafficking molecule synaptotagmin-1 Dg-syt in adult females of Dinophilus gyrociliatus. The expression pattern is shown in ventral $(\mathbf{a}, \mathbf{c})$ and lateral (ventral side to the left, $\mathbf{b})$ views as well as in a schematic drawing in ventral view $(\mathbf{d})$. Dg-syt labels all perikarya of the brain, thereby resembling the pattern of $\mathrm{Dg}-\mathrm{six} 3 / 6$, and can be furthermore shown around the mouth opening and-in approximately $20 \%$ of animals - also labels the ganglionic accumulations in the anterior region of the ventral nerve cord. acom $1-4$ anterior commissure of segment 1-4, br brain, cb 1-6 ciliary band 1-6, com 1-3 commissural set of segment 1-3, fg frontal gland, Ipmn lateral paramedian nerve, mcom 1-4 median commissure of segment $1-4$, mo mouth opening, mpmn median paramedian nerve, mvn medioventral nerve, $n p$ neuropil, $p c o m 1-4$ posterior commissure of segment $1-4$, phb pharyngeal bulb, stnr stomatogastric nerve ring, vinc ventrolateral nerve cord 


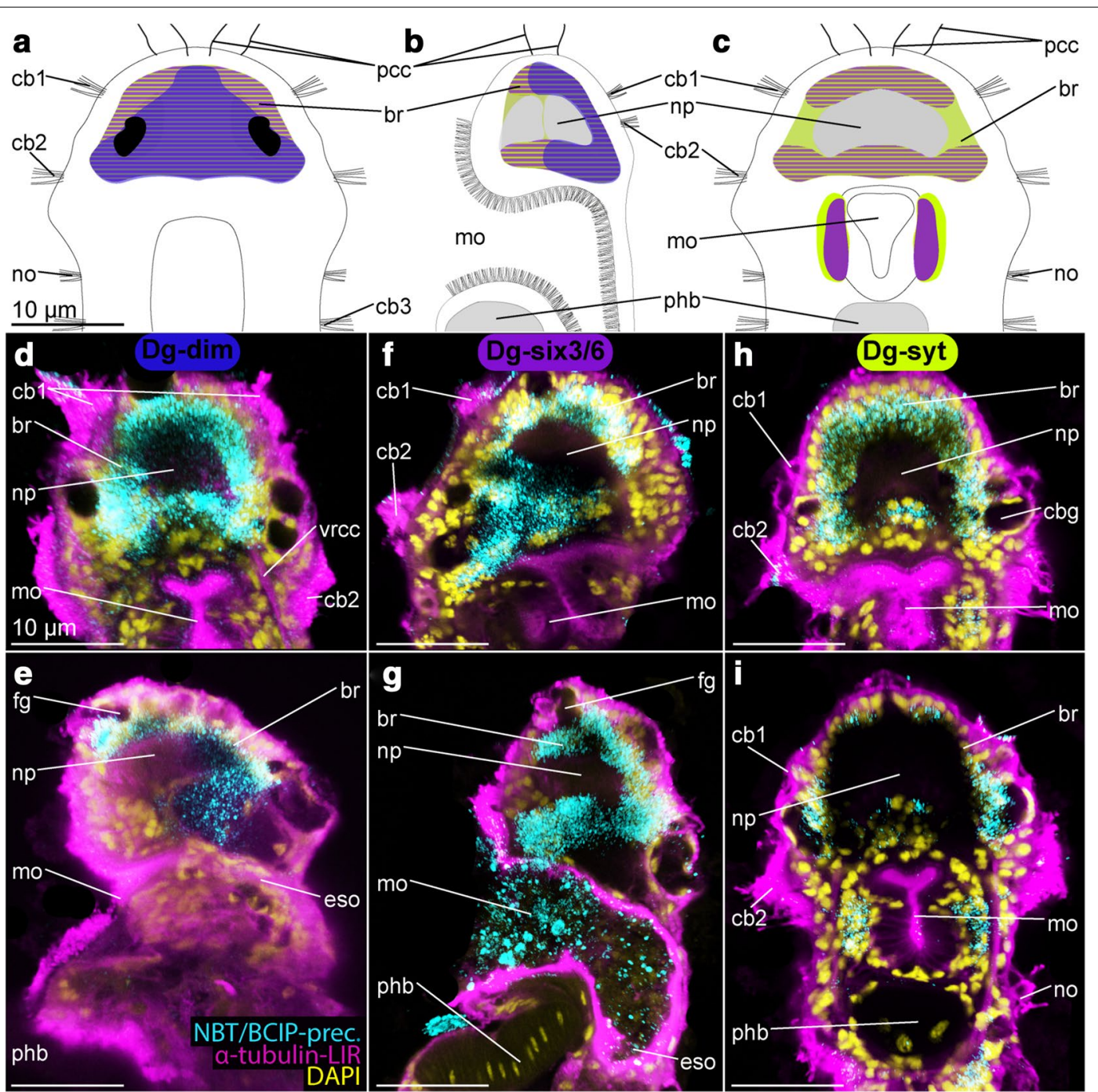

Fig. 5 Expression pattern of Dg-dim, Dg-six3/6 and Dg-syt and in adult females of Dinophilus gyrociliatus, which characterize a mediodorsal, probably neurosecretory region of the brain. The assumed overlap of the expression domains is shown in a schematic drawing in dorsal (a), lateral (ventral side to the left, b) and ventral views (c), with similar color coding than employed in the other plates (Dg-dim—dark blue, Dg-six3/6—purple, Dg-syt— light green). Reflective microscopy was used to correlate the NBT/BCIP-precipitation pattern (shown in $\mathbf{d}$-i in cyan) with acetylated a-tubulin-like immunoreactivity (acetylated a-tubulin-LIR, pink) and DAPI-labeled nuclei (yellow). $\mathbf{d}$ Horizontal section of the ventral region of the brain and $\mathbf{e}$ horizontal section of the dorsomedian region of the brain with Dg-syt expression domains, $\mathbf{f}$ oblique section of the median region of the brain and $\mathbf{g}$ sagittal section through the brain with Dg-six3/6 expression domains, $\mathbf{h}$ horizontal section of the dorsal region of the brain and $\mathbf{i}$ sagittal section through the brain with Dg-dim expression domains. Scale bar is $10 \mu \mathrm{m}$ in all images. br brain, cb ciliary band, cbg ciliary band gland, eso esophagus, $f g$ frontal gland, mo mouth opening, $n$ nephridium, no nuchal organ, $n p$ neuropil, $p c b$ prostomial ciliary band, pcc prostomial compound cilia, phb pharyngeal bulb, $v c f$ ventral ciliary field, $v r c c$ ventral root of the circumesophageal connective

and $P$. dumerilii [35], which express synaptotagmin-1 in both the brain and the ventral nerve cords, we detected expression of $D g$-syt in the majority of perikarya of the brain in females of $D$. gyrociliatus (Figs. $4 \mathrm{a}-\mathrm{d}, 5 \mathrm{~h}, 8 \mathrm{a}-\mathrm{c}$ ) and in ganglionic accumulations along the anterior ventral nerve cord in about $20 \%$ of all investigated specimens (Fig. 4c), which is possibly due to the small amount and weak concentration of cell nuclei at the commissures, in particular when compared to, e.g., C. teleta [33]. It was observed that these cellular accumulations associated with the commissures are strongest in young females and get more dilated in older/pregnant specimens.

\section{Discussion}

Molecular patterning of the brain in adult females of $D$. gyrociliatus

Nine out of the eleven evolutionarily conserved neural genes analyzed in this study show domains mainly within 

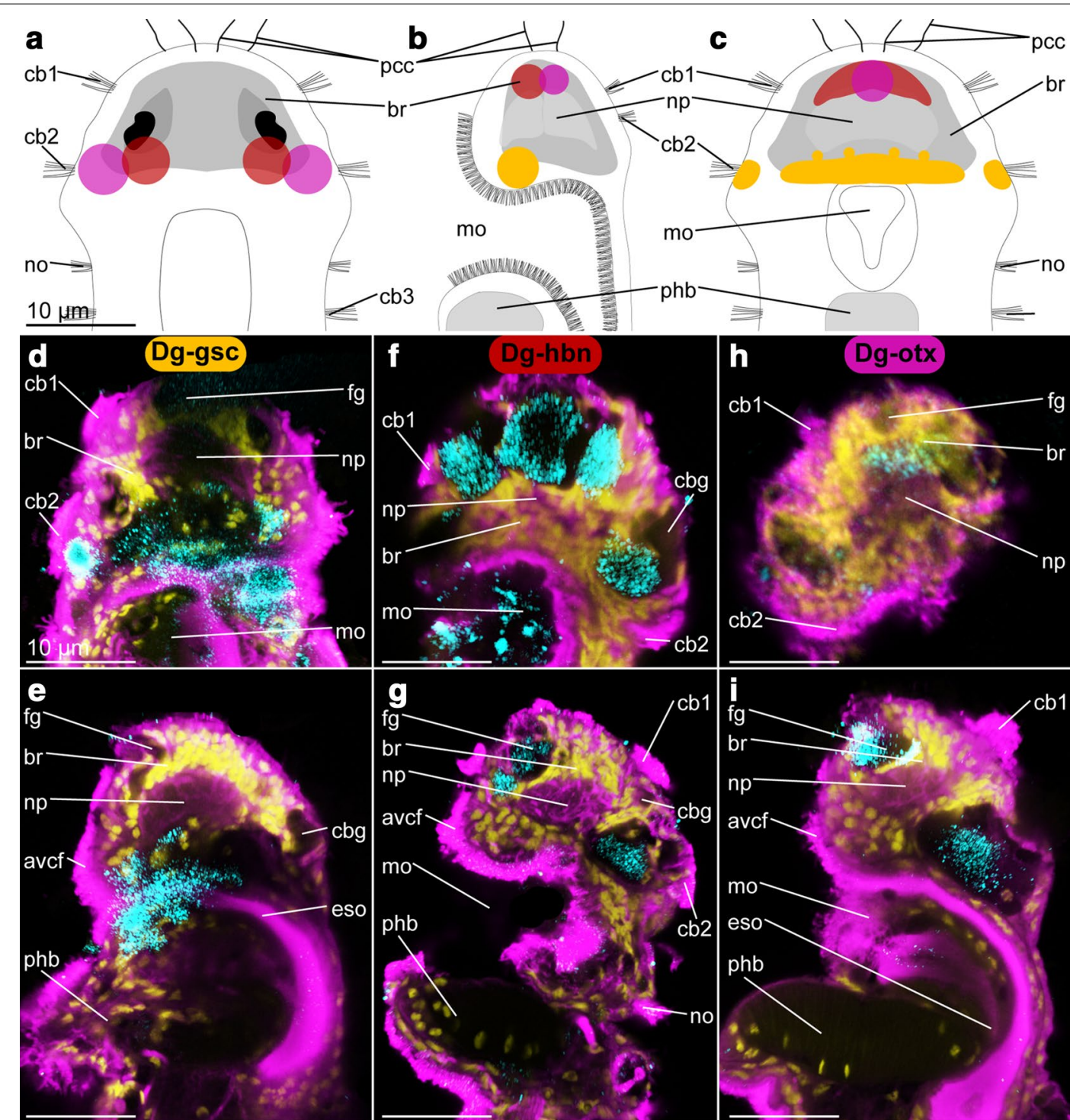

Fig. 6 Expression pattern of Dg-gsc, Dg-hbn and Dg-otx in adult females of Dinophilus gyrociliatus, which characterize an anteroventral median and posteroventral lateral domain, possibly related to sensory and locomotory cilia. The assumed overlap of the expression domains is shown in a schematic drawing in dorsal $(\mathbf{a})$, lateral (ventral side to the left, $\mathbf{b})$ and ventral views $(\mathbf{c})$, with similar color coding than employed in the other plates (Dg-gsc - orange, Dg-hbn—red, Dg-otx-pink). Reflective microscopy was used to correlate the NBT/BCIP-precipitation pattern (shown in $\mathbf{d}$-i in cyan) with acetylated a-tubulin-like immunoreactivity (acetylated a-tubulin-LIR, pink) and DAPI-labeled nuclei (yellow). $\mathbf{d}$ Horizontal section of the ventral region of the brain and $\mathbf{e}$ sagittal section through the brain with Dg-gsc expression domains, $\mathbf{f}$ horizontal section of the ventral region of the brain and $\mathbf{g}$ sagittal section through the lateral region of the brain with Dg-hbn expression domains, $\mathbf{h}$ horizontal section through the dorsal brain and $\mathbf{i}$ sagittal section through the mediolateral region of the brain with $\mathrm{Dg}$-otx expression domains. Scale bar is $10 \mu \mathrm{m}$ in all images. avcf anteroventral ciliary field, br brain, $c b$ ciliary band, cbg ciliary band gland, eso esophagus, fg frontal gland, mo mouth opening, $n p$ neuropil, no nuchal organ, $p c b$ prostomial ciliary band, $p c c$ prostomial compound cilia, ph pharynx, phb pharyngeal bulb

or closely adjacent to the brain (Dg-dim, $D g$-foxg, $D g$-gsc, Dg-hbn, Dg-otp, Dg-otx, Dg-pax6, Dg-six3/6 and Dg-syt, Figs. 1, 2, 3, 4, 5, 6, 7, 8; Additional file 9). Exceptions are transcription factors $D g-n k 2.1$, expressed in the fore- and hindgut in addition to the domains in the brain (Figs. 3j1, 8a-c; Additional file 9), and $D g-n k 2.2$, not detected in the brain, but in the mid- and hindgut (Fig. 3m-o; Additional file 9).

$D g$-gsc is not exclusively expressed in the brain, but also in two condensed domains close to the second prostomial ciliary band (Figs. 2a-c, 6d, e, 8c), which are associated with neither the brain nor the digestive 

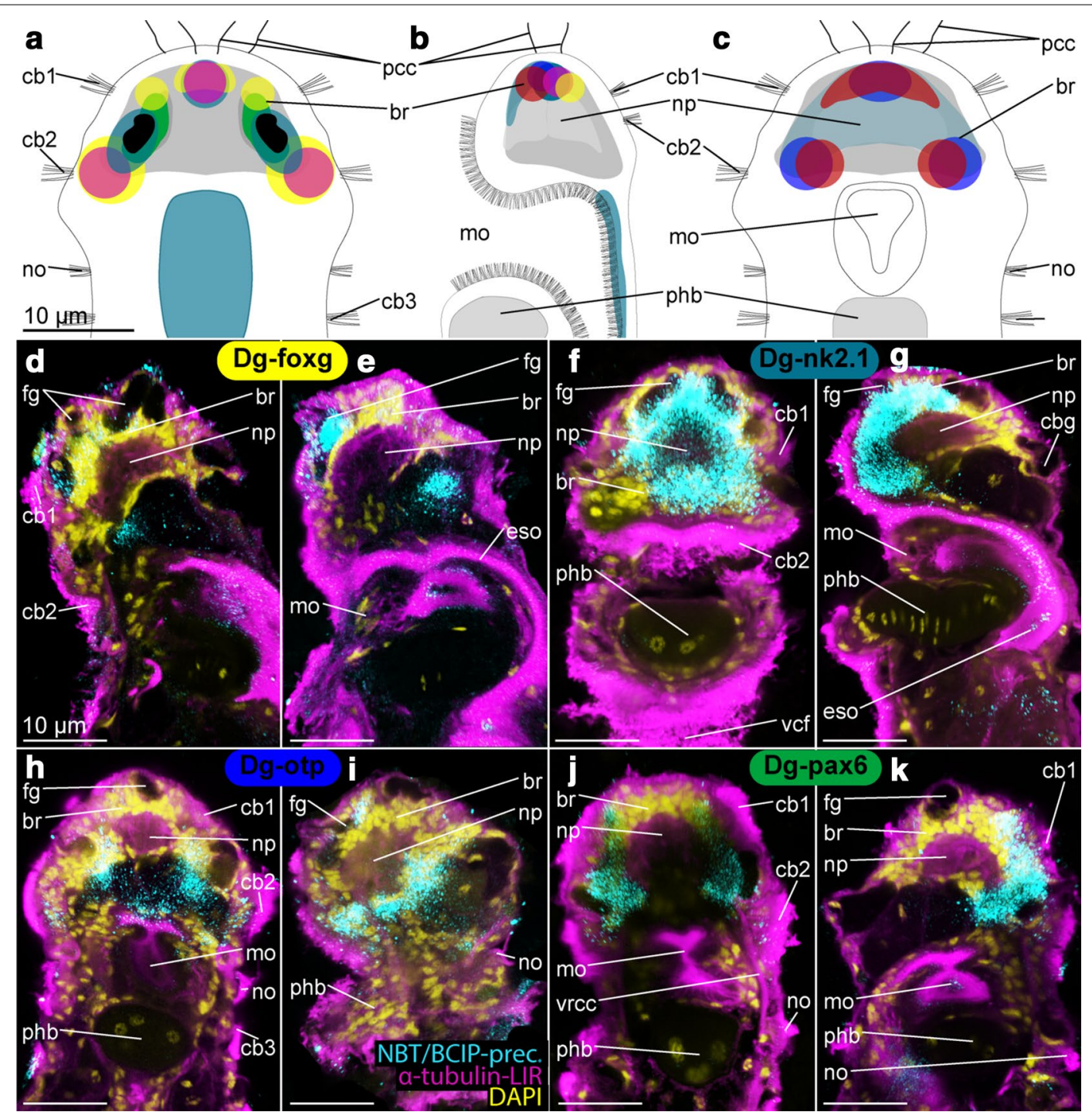

Fig. 7 Expression pattern of Dg-foxG, Dg-nk2.1, Dg-otp and Dg-pax6 in adult females of Dinophilus gyrociliatus, which are labeling a probable dorsal sensory region including innervation of eyes and sensory cilia ( $\mathrm{Dg}$ - $h b n$ and $\mathrm{Dg}$-otx are included in the schematic drawings, based on information shown in previous plates). The assumed overlap of the expression domains is shown in a schematic drawing in dorsal (a), lateral (ventral side to the left, b) and ventral views (c), with similar color coding than employed in the other plates (Dg-foxg-yellow, Dg-hbn-red, Dg-nk2.1—-turquoise, Dg-otp—dark purple, Dg-otx — pink, Dg-pax6—dark green). Reflective microscopy was used to correlate the NBT/BCIP-precipitation pattern (shown in d-k in cyan) with acetylated a-tubulin-like immunoreactivity (acetylated a-tubulin-LIR, pink) and DAPI-labeled nuclei (yellow). d Sagittal section of the lateral region of the brain and $\mathbf{e}$ sagittal section of the median region of the brain with Dg-foxg expression domains, $\mathbf{f}$ horizontal section of the ventral region of the brain and $\mathbf{g}$ sagittal section through the median region of the brain with Dg-nk2.1 expression domains, $\mathbf{h}$ horizontal section of the ventral region of the brain and $\mathbf{i}$ sagittal section through the brain with Dg-otp expression domains, $\mathbf{j}$ horizontal section through the dorsal region of the brain and $\mathbf{k}$ oblique section through the dorsal region of the brain with Dg-pax6 expression domains. br brain, cb ciliary band, eso esophagus, mo mouth opening, no nuchal organ, $n p$ neuropil, pcb prostomial ciliary bands, pcc prostomial compound cilia, phb pharyngeal bulb, vcf ventral ciliary field

tract. Clearly demarcated domains resembling this pattern cannot be found in either C. teleta or P. dumerilii [74, 75]. Although goosecoid domains in the stomodeum and foregut region are present in the trochophore larva of P. dumerilii (Fig. 8e, [75]) as well as the early larva of C. teleta (Fig. 8d, [74]), they are limited to the anterior portion of the pharyngeal epithelium in adult female $D$. gyrociliatus (Figs. 2a-c, 6d, e, 8b, c; Additional file 9). The gsc-positive domains within the brain vary between the investigated annelids. They are restricted to the foregut in trochophore larvae of $P$. dumerilii (Fig. 8e, [75]), but localized in the posterior part of the brain, lateral to the 


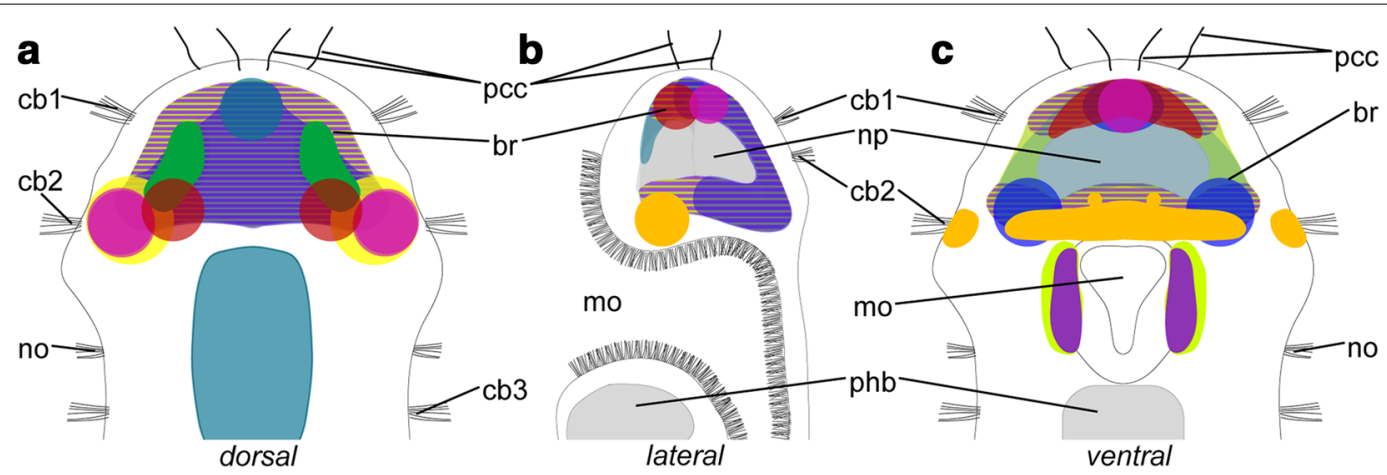

Dinophilus gyrociliatus

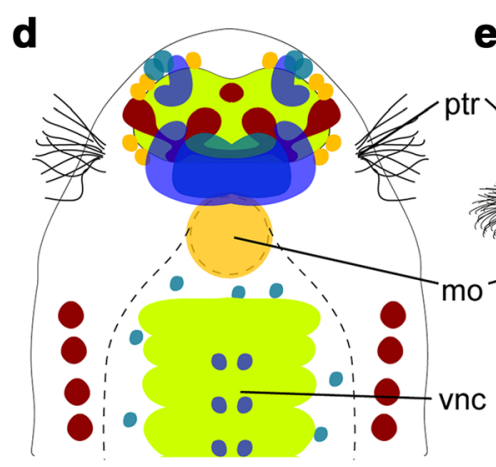

Capitella teleta / sp. 1 Larva stage 6

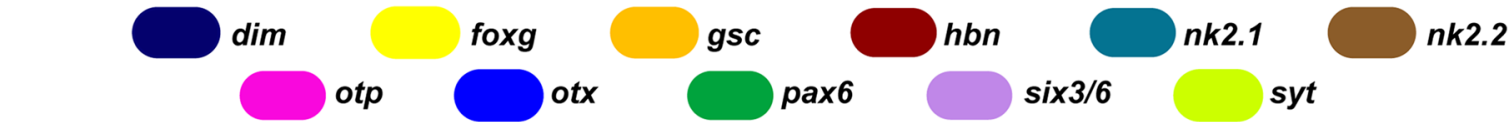

e

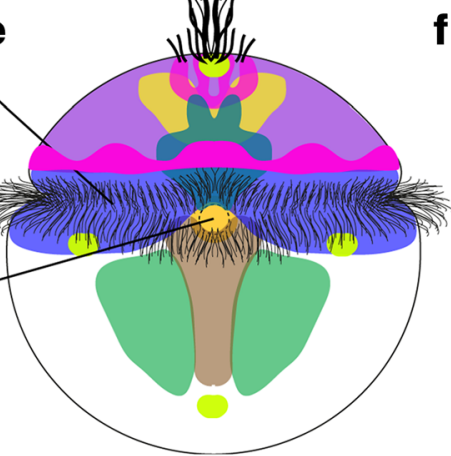

Platynereis dumerilii Trochophora-larva

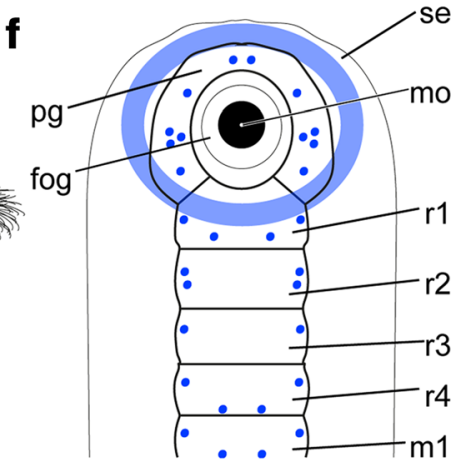

Helobdella triseralis Larva stage $8 / 9$

Fig. 8 Axial patterning in the brain of adult females of Dinophilus gyrociliatus and comparison of orthologous gene expression in stage 8 larva of Capitella teleta, a trochophore larva of Platynereis dumerilii and a stage 8/9 larva of Helobdella triseralis. a-c Schematic interpretation based on singleprobe NBT/BCIP-precipitation patterns acquired in this study (Dg-dim, Dg-foxG, Dg-gsc, Dg-hbn, Dg-nk2.1, Dg-otp, Dg-otx, Dg-pax6, Dg-six3/6 and $D g$-syt) in dorsal (a), midsagittal (ventral side to the left, $\mathbf{b}$ ) and ventral (c) views. d Ventral view of the trochophore larva in P. dumerilii inferred from $[23,35,40]$, e ventral view of the anterior region in C. teleta inferred from [16, 33], f ventral view of embryonic stage 8/9 in Helobdella triseralis [41]. The overlap of genes is interpreted from this and previous studies. fog foregut, mo mouth opening, $m 1$ segmental midbody ganglion, $n p$ neuropil, pcc prostomial compound cilia, $p c b$ prostomial ciliary bands, pg prostomial ganglion, ptr prototroch, $r 1-r 4$ segmental rostral ganglion, se surface ectoderm, vnc ventral nerve cord

brain and in the region of the circumesophageal connectives in late larvae of C. teleta (larval stage 7-8, Fig. 8d, [74]) and adult D. gyrociliatus (Figs. 2a-c, 8b, c; Additional file 9). Our findings thereby suggest that goosecoid can vary in its expression in the brain and stomatogastric system in Annelida.

$D g-h b n$ is expressed in distinctive parts of the brain in adult females of D. gyrociliatus (Figs. 2d-f, 6f, g, 8a-d), as also observed in C. teleta [16], with several patches in the posterior part of the brain extending to the anterior (mainly in the latter). Additionally, segmentally arranged domains of CapI-hbnl in C. teleta were detected in association with chaetal sacs lateral along the body length [16], which were not found in D. gyrociliatus females.
Homeobrain is therefore probably involved in neuronal differentiation in the cerebral ganglia and brain in annelids.

Dg-otp is expressed both in a median, demarcated domain on the ventroanterior side and one pair of lateral patches in the ventroposterior region of the brain in D. gyrociliatus (Figs. 2g-i, 7h, i, 8a-c; Additional File 9). The anterior domain seems to occur within a $D g$-six3/6positive region of the brain, which resembles the situation found in invertebrate apical organs and especially in the apical organ of $P$. dumerilii, where orthopedia is present in presumptive serotonergic cells [22, 23]. In adult females of $D$. gyrociliatus, however, Dg-otp is not related to any serotonergic component, since these are restricted 
to the dorsoposterior region of the brain (pers. obs., Fig. 1g, [45]). More posteriorly, otp is expressed in cells that might be involved in forming the multiciliated cells of the prototroch in the trochophore larvae of $P$. dumerilii [23]. Although information about its expression in $C$. teleta is missing, the expression of otp in cells related to several cells of the second prostomial ciliary band in $D$. gyrociliatus (Figs. 2g-i, 8a-c) is thus probably an indication for the remnants of the prototroch in the later.

$D g$-otx is expressed broadly as continuous band in the ventroanterior region of the brain as well as in one pair of lateral domains in the posterior region of the brain. It is therefore overlapping with $D g$-six $3 / 6$ in female $D$. gyrociliatus in both the anterior and the posterior part of the brain (Figs. $2 \mathrm{~g}-\mathrm{i}, 8 \mathrm{a}-\mathrm{c}$ ). This is in contrast to the expression detected in $P$. dumerilii trochophore larvae (Fig. 8e), where otx demarcates the ventral expression range of six3/6 posterior to the cells expressing the PRD class gene otp, tracing the prototroch [21, 23, 34]. It is only partly in concordance with the pattern of the transcription factor otx in C. teleta, which develops domains anterolateral and posteromedian in the brain, but also in the foregut, posterior region of the midgut, hindgut and the medioventral ectoderm [74]. The expression domains of the PRD class gene $o t \mathrm{x}$ are thus little conserved among the anterior neural regions in the annelid species analyzed so far. Further studies have to ascertain whether the exclusiveness of six $3 / 6$ and otx as observed in the apical organ and the posterior region of the brain in $P$. dumerilii trochophore larvae [21,34] or the broad expression in the brain and digestive system as detected in C. teleta [74] are also present in the meiofaunal annelid during earlier developmental stages. The differences among the three annelids thereby might be the result of temporal variability of this gene's activation rather than an expression in different domains.

$D g$-pax6 is expressed in extended patches in the regions of the eyes dorsal to the neuropil in the brain of $D$. gyrociliatus (Figs. $2 \mathrm{~m}-\mathrm{o}, 8 \mathrm{a}-\mathrm{c}$ ). This matches the transcription factor's proposed role in eye development across Bilateria [40, 76], based on its bilateral brain domains, being the most common location of photoreceptors $[9,35]$. The lateral patterns found in the median coronal plane of the brain of D. gyrociliatus might also indicate that it is involved in specifying the mediolateral axis of the central nervous system as it has been suggested for the bilaterian ancestor [35].

$D g$-foxg is expressed in domains in the anterior and the posterior region of the brain, which resembles the pattern detected with $D g$-otp and Dg-otx (Figs. $2 \mathrm{~g}-\mathrm{l}, 3 \mathrm{a}-\mathrm{c}$, $8 \mathrm{a}-\mathrm{c}$ ). The anterior domain is constituted by an interconnected series of spots, while there is a pair of dorsolateral demarcated domains in the posterior part of the brain (Figs. 3a-c, $8 \mathrm{a}-\mathrm{c}$ ). This seems to be contradicting the finding in the trochophore larvae of $P$. dumerilii, where this gene is related to the developing cerebral ganglia and especially the mushroom bodies [9], and thereby labels more central neural structures (Fig. 8e). The different patterns in the annelids studied so far might either be related to the developmental stage the animals are in (trochophore larvae in P. dumerilii vs. adults in D. gyrociliatus) or to the different organization of the nervous system (compartmentalized in $P$. dumerilii vs. compact and seemingly unstructured in D. gyrociliatus). Further information in C. teleta (adult and developmental stages), which has an unstructured brain, but indirect development, will aid the reconstruction of a general annelid pattern.

All perikarya of the brain with the exception of the ventrolateral sides also express $D g$-six $3 / 6$ (Figs. $3 \mathrm{~d}-\mathrm{f}, 5 \mathrm{f}$, g, 8a-c; Additional file 9), which therefore shows broad overlap with the other genes used in this study (Fig. 8ac). This supports previous findings about six3/6 playing a major role in demarcating the anterior or anteromedian region of the brain in several invertebrate groups $[22,34,77]$, and especially in patterning the larval apical organ and cerebral ganglia in the annelids C. teleta and $P$. dumerilii (Fig. 8d, e, [23]).

The most elaborate dorsal pattern is formed by $D g$-dim, which is strongest along the dorsal midline while expanding antero- and posteromedially in the brain (Figs. 3g-i, $5 \mathrm{~d}$, e, 8a-c; Additional file 9). The transcription factor dimmed, which is suggested to be involved in patterning neurosecretory cells during early and larval development, is detected in several cells of both the brain and the ventral nerve cord in the ecdysozoan D. melanogaster [71, 72] and in few cells in the apical organ of the trochophore larva of the annelid P. dumerilii [70]. In Drosophila, the protein DIMMED directly activates the neuropeptideamidating enzyme PHM [72]. Since amidated neuropeptides are generally conserved between related animal lineages, e.g., spiralian groups [78], further work in more annelid species is essential to better understand the evolution of dimmed-positive neurons.

$D g-n k 2.1$ and $D g-n k 2.2$ do not exclusively pattern the brain, since $D g-n k 2.1$ is also expressed in the roof of the foregut and the entire hindgut (Figs. 3j-l, 7f, g, 8a-c; Additional file 9), and $D g$ - nk2.2 labels the midgut and is completely absent from the adult brain of the female D. gyrociliatus (Fig. 3m-o; Additional file 9). Capitella teleta shows similar anterolateral (and posteromedian) expression domains of $n k 2.1$ in the brain, which are supplemented by strongly labeled regions in the fore- and hindgut, as well as spot-like expression in the remaining digestive tract (Fig. 8d (domain in the foregut shadowed by broader region of otx), [74]). In $P$. dumerilii, $n k 2.1$ 
was found associated with the mouth opening and the ventral side of the trochophore larva, where it extends from approximately the apical organ (where it has a broad expression domain) toward the mouth opening, overlapping with six3/6 (Fig. 8e, [18, 22, 23]). This latter somewhat discrepant pattern emphasizes the need for developmental studies of D. gyrociliatus for proper comparison, but the overall resemblance among all hitherto studied annelids supports a probable function of the transcription factor $n k 2.1$ in differentiating the ventral region of the brain as well as the digestive system in annelids.

The transcription factor $n k 2.2$ strictly complements the pattern of pax6 in the developing nervous system in the trochophore larva of $P$. dumerilii (Fig. 8e, [35]). It does not have domains anterior to the prototroch, but is expressed in a slender region of midline cells, thereby labeling the medial edges of the fusing neuroectoderm and possibly lining the prototroch lateral to the stomodeum (Fig. 8e, [35]). In later stages, the domain is limited to the midventral region between the prominent nerve cords [35]. Although we did not observe expression of $D g-n k 2.2$ in the brain in adult D. gyrociliatus, further expression analyses in juveniles and embryonic stages will help uncover possible neural-related expression of $n k 2.2$ in this annelid species.

Adult female D. gyrociliatus show expression of $D g$ syt in the brain, but also in the ganglionic accumulations along the ventral nerve cord (associated with the commissural sets, Figs. 4c, d, $8 \mathrm{a}-\mathrm{c}$ ), which is similar to previous findings in other annelids such as $C$. teleta and $P$. dumerilii [33, 35]. Synaptotagmin-1 is expressed in individual cells of the apical organ or early adult brain and along the ventral nerve cords, seemingly involved in the formation of the ganglionic cord of $C$. teleta and $P$. dumerilii $[33,35]$. We therefore suggest that $D g$-syt plays a similar role in neural specification in D. gyrociliatus. $[29,31]$.

Altogether, our findings indicate that the overall patterning of the brain in adult females of $D$. gyrociliatus resembles the molecular regionalization observed in larval stages of previously examined annelids (e.g., [16, 23, $37,40,79,80])$. We furthermore identified that (1) $D g$ dim, $D g$-six3/6 and $D g$-syt pattern a mediodorsal, probably neurosecretory region, which also extends ventrally anterior and posterior to the neuropil (Fig. 5), (2) $D g$ foxg, $D g$-gsc and Dg-otx demarcate a population of cells underneath the second ciliary band of the prostomium (Fig. 6), and (3) Dg-foxg, Dg-hbn, Dg-otp, Dg-otx, Dg$n k 2.1$ and $D g$-pax6 specify sensory regions in the brain such as the anterior neural region (probably related to the prostomial compound cilia), the eyes and the base of the nerves extending from the nuchal organs to the neuropil
(Fig. 7). However, more detailed investigations of the embryonic and juvenile stages in D. gyrociliatus will provide a better insight into the role of these genes during neural development.

\section{Miniaturization and the molecular patterning of the brain in Annelida}

Meiofaunal species and their organ systems have not been included in previous studies of annelid and spiralian diversity although their inclusion will likely provide additional insight into how conserved molecular networks are modified to give rise to differently organized tissues. In this context, it is still unclear whether neural genes, which are broadly conserved in macroscopic representatives of Protostomia and Deuterostomia [52, 53, 81, 82, 83], maintain their relative expression domains in brains of microscopic size and limited cell number, as those found in interstitial animals. Our findings demonstrate that the relative position of genes such as foxg, orthopedia, homeobrain, six $3 / 6$ and synaptotagmin-1 seems to be similar between $D$. gyrociliatus and other annelids andto some extent-Spiralia (Figs. 1, 2, 3, 4, [16, 23, 33, 35]), although the approximate number of cells in the respective domains is lower. Importantly, these observations uncover underlying substructures in the small, compact brain of $D$. gyrociliatus. The fact that we observed similar molecular domains in D. gyrociliatus and other annelid taxa suggests that the relative extent of the expression areas is maintained regardless of the life stage of the animal. This furthermore suggests that the cells in the brain of $D$. gyrociliatus do not show a higher degree of multifunctionality, but that in these microscopic brains probably fewer cells are assigned to certain functions. Further studies unraveling the earlier developmental stages of D. gyrociliatus as well as the dwarf male with an even smaller brain consisting of only 42 cells $[63,64]$ are therefore highly warranted. They will not only help to generate a broader base for comparisons between annelid and/or spiralian taxa, but also deepen our understanding of the conservation of genetic patterning of the brain in species with different neuroanatomies adapted to particular ecological niches and possibly varying requirements in different life stages (encapsulated embryos, free-swimming larvae, adults).

\section{Conclusions}

Adult females of D. gyrociliatus express dim, foxg, gsc, $h b n$, otp, otx, nk2.1, pax6, six3/6 and syt almost exclusively in the brain, and their pattern is consistent with the domains described in larval stages in the macrobenthic annelid species $P$. dumerilii and C. teleta (e.g., $[16,21,23]$ ). Although the brain does not show elaborate morphological substructures (e.g., mushroom bodies, optic lobes/ 
tracts), $P R D$ box and FOX genes and $n k 2.1$ and the transcription factor dimmed are expressed in specific areas in the brain, with moderate overlap between their patterns. We therefore suggest that the adult brain in this meiofaunal annelid is also regionalized and possibly shows more similarities with late larval stages in C. teleta $[16,33]$ than suggested by gross morphology alone $[45,46]$. The overall expression pattern in the anterior nervous system as described previously in several annelid species $[22,23]$ is also observed in the adult brain of D. gyrociliatus, despite the interspecific differences in the organ size and developmental mode. Therefore, we propose that the underlying patterning mechanism of the brain is independent of whether the animals show direct or indirect development and of the final complexity of this anterior neural region. To what extend the molecular regionalization of the brain can be correlated with different functions of the respective areas has to be tested in future studies, also including earlier developmental stages.

\section{Additional files}

Additional file 1. Sequences for gene orthology assignment. Amino acid sequences for Dinophilus gyrociliatus genes used in this study as well as related proteins from other animals, retrieved from NCBI (html://http:// ncbi.nlm.nih.gov) and Joint Genome Institute (http://genome.jgi-psf.org/ Capca1/Capca1.home.html for Capitella teleta; http://genome.jgi-psf.org/ Lotgi1/Lotgi1.home.html for Lottia gigantea; http://genome.jgi-psf.org/ Nemve1/Nemve1.home.html for Nematostella vectensis; http://genome. jgi-psf.org/Triad1/Triad1.home.html for Trichoplax adhaerens) including all information for the Additional files 3, 4, 5, 6, 7 and 8. http://genome.jgi-psf. org/Capca1/Capca1.home.html for Capitella teleta; for Lottia gigantea; for Nematostella vectensis; for Trichoplax adhaerens) including all information for the Additional files 3, 4, 5, 6, 7 and 8 .

Additional file 2. Primer sequences used for the respective genes in Dinophilus gyrociliatus. Matching primer pairs were designed using MacVector (MACVECTOR, INC., Cambridge, UK) and the "Sequencing Primers/Probes"-tool. Pairs were chosen based on their length (20-25 bp), G-C-content ( $45-55 \%$, manually checked for not more than 3 C or $\mathrm{G}$ in a row) and similar working temperature.

Additional file 3. Phylogenetic analysis of Dg-syt. Phylogenetic tree of the membrane-trafficking protein SYNAPTOTAGMIN-1 with emphasis on Dg-syt (which is highlighted in the tree), supporting its orthology assignment. Protein alignments were made using MUSCLE [67] and Bayesian phylogenetic analysis was performed using MrBayes [68], with settings according to [22]. Each analysis was run for 30,000,000 generations sampled every 1000 generations in four runs. A consensus tree and posterior probabilities for each branch were calculated prior to visualization of the tree with FigTree and edition in Adobe Illustrator 2015CC. All sequences used are listed in Additional file 1.

Additional file 4. Phylogenetic analysis of PRD class genes Dg-gsc, Dg-hbn, Dg-otp, Dg-otx and Dg-pax6. Phylogenetic tree of the paired box genes with emphasis on the genes used in this study (which are highlighted in the tree), supporting their orthology assignments. Protein alignments were made using MUSCLE [67] and Bayesian phylogenetic analysis was performed using MrBayes [68], with settings according to [22]. Each analysis was run for 30,000,000 generations sampled every 1000 generations in four runs. A consensus tree and posterior probabilities for each branch were calculated prior to visualization of the tree with FigTree and edition in Adobe Illustrator 2015CC. All sequences used are listed in Additional file 2.
Additional file 5. Phylogenetic analysis of $D g$-foxG. Phylogenetic tree of the forkhead box genes with emphasis on Dg-foxG (which is highlighted in the tree), supporting its orthology assignments. Protein alignments were made using MUSCLE [67] and Bayesian phylogenetic analysis was performed using MrBayes [68], with settings according to [22]. Each analysis was run for 30,000,000 generations sampled every 1000 generations in four runs. A consensus tree and posterior probabilities for each branch were calculated prior to visualization of the tree with FigTree and edition in Adobe Illustrator 2015CC. All sequences used are listed in Additional file 1.

Additional file 6. Phylogenetic analysis of $D g-5 i x 3 / 6$. Phylogenetic tree of the six class genes with emphasis on $\mathrm{Dg}$-six3/6 (which is highlighted in the tree), supporting its orthology assignments. Protein alignments were made using MUSCLE [67] and Bayesian phylogenetic analysis was performed using MrBayes [68], with settings according to [22]. Each analysis was run for 30,000,000 generations sampled every 1000 generations in four runs. A consensus tree and posterior probabilities for each branch were calculated prior to visualization of the tree with FigTree and edition in Adobe Illustrator 2015CC. All sequences used are listed in Additional file 1.

Additional file 7. Phylogenetic analysis of $D g$-dim. Phylogenetic tree of the dimmed genes with emphasis on Dg-dim (which is highlighted in the tree), supporting its orthology assignments. Protein alignments were made using MUSCLE [67] and Bayesian phylogenetic analysis was performed using MrBayes [68], with settings according to [22]. Each analysis was run for 30,000,000 generations sampled every 1000 generations in four runs. A consensus tree and posterior probabilities for each branch were calculated prior to visualization of the tree with FigTree and edition in Adobe Illustrator 2015CC. All sequences used are listed in Additional file 1.

Additional file 8. Phylogenetic analysis of $D g-n k 2.1$ and $D g-n k 2.2$. Phylogenetic tree of the NK-homeobox genes with emphasis on the genes used in this study (which are highlighted in the tree), supporting their orthology assignments. Protein alignments were made using MUSCLE [67] and Bayesian phylogenetic analysis was performed using MrBayes [68], with settings according to [22]. Each analysis was run for 30,000,000 generations sampled every 1000 generations in four runs. A consensus tree and posterior probabilities for each branch were calculated prior to visualization of the tree with FigTree and edition in Adobe Illustrator 2015CC. All sequences used are listed in Additional file 1.

Additional file 9. Brain-specificity of gene expression patterns for the genes tested. Dg-syt, Dg-gsc, Dg-hbn, Dg-otp, Dg-otx, Dg-pax6, Dg-foxG, $D g$-six3/6 and Dg-dim, while $D g-n k 2.1$ also labels the fore- and hindgut and $D g-n k 2.2$ is only expressed in the posterior midgut. The light staining in the stomach of specimens labeled with Dg-otx and Dg-dim is an artefact, since precipitation was retained between the stomach content of the animals. Dg-otx and Dg-pax6 are not shown in strict dorsoventral orientation, since the pharyngeal bulb is too extruded to balance the animals dorsoventrally at high magnification.

\section{Abbreviations}

acom: anterior commissure; an: anus; br: brain; cb: ciliary band; cbg: ciliary band gland; cmvn: circumesophageal connective joining the medioventral nerve posteriorly; com: segmental commissure/commissural set; cvln: circumesophageal connective joining the ventrolateral nerve cords; drcc: dorsal root of the circumesophageal commissure; eso: esophagus; ey: eye; fog: foregut; fg: frontal gland; fpk: perikaryon with FMRFamide-like immunoreactivity(LIR); Ipmn: lateral paramedian nerve; mcom: median commissure; mo: mouth opening; mpmn: median paramedian nerve; mv: medioventral nerve; $\mathrm{m} 1$ : segmental midbody ganglion; nc: nerve linking ciliary structure to the neuropil; no: nuchal organ; np: neuropil; pcb: prostomial ciliary band; pcc: prostomial compound cilia; pcom: posterior commissure; pg: prostomial ganglion; phb: pharyngeal bulb; ptr: prototroch; vnc: ventral nerve cord; pyg: pygidium; r1-r4: segmental rostral ganglion; se: surface ectoderm; scom: subrectal commissure; spk: perikaryon with serotonin-like immunoreactivity (LIR); stnr: stomatogastric nerve ring; sto: stomach; tcom: terminal 
commissure; vcf: ventral ciliary field; vlnc: ventrolateral nerve cord; vrcc: ventral root of the circumesophageal connective.

\section{Authors' contributions}

All authors designed the study, AK and JMMD cloned genes and produced riboprobes, AK maintained the animal cultures, performed the in situ hybridization experiments, conducted phylogenetic analyses and drafted the manuscript. All authors read and approved the final manuscript.

\section{Acknowledgements}

We want to thank Yvonne Müller, Aina Børve and Anlaug Boddington for their help in rearing the animals and support during the laboratory work. We are very grateful to Nicolas Bekkouche, who provided riboprobes for Dg-pax6. Additionally, we want to thank Niels Daubjerg (Marine Biology Section, University of Copenhagen, Denmark) to permit the use of the Zeiss Axio Imager 2 Microscope with corresponding cameras and computer. The mining of the transcriptome of Dinophilus gyrociliatus was enormously facilitated due to assemblage and continuous support by Bruno C. Vellutini. Furthermore, we would like to thank Brett Gonzalez for helpful advice in analyzing the orthology of the genes used in this study. Finally, we want to thank three anonymous reviewers for their comments to improve the manuscript.

\section{Competing interests}

The authors declare that they have no competing interests.

\section{Availability of data and material}

All data generated or analyzed during this study are included in this published article and its supplementary information files. Sequences for the genes used in this study are registered with GenBank (GenBank Accession Numbers KX555473-KX555483), the raw reads of the transcriptome have been deposited at SRA: SRA Experiment: SRX2030658, and the in situ hybridization protocol for Dinophilus gyrociliatus is detailed in the Materials and Methods section of this article.

\section{Funding}

This study was funded by Grant No. 1025442 ("How small animals provide clues to large scale questions") assigned to Katrine Worsaae by the Villum Foundation and the University of Copenhagen and the core budget of the Sars Centre.

Received: 27 July 2016 Accepted: 17 August 2016

Published online: 30 August 2016

\section{References}

1. Orrhage L, Müller MCM. Morphology of the nervous system of Polychaeta (Annelida). Hydrobiologia. 2005;535(536):79-111.

2. Müller MC. Polychaete nervous systems: ground pattern and variations - CLS microscopy and the importance of novel characteristics in phylogenetic analysis. Integr Comp Biol. 2006;46:125-33.

3. Purschke G. Annelida: Basal groups and Pleistoannelida. In: SchmidtRhaesa A, Harzsch S, Purschke G, editors. Structure and evolution of invertebrate nervous systems. 1st ed. Oxford: Oxford University Press; 2015. p. 254-312.

4. Müller MC, Henning L. Ground plan of the polychaete brain-I. Patterns of nerve development during regeneration in Dorvillea bermudensis (Dorvilleidae). J Comp Neurol. 2004;471:49-58.

5. Heuer CM, Müller CH, Todt C, Loesel R. Comparative neuroanatomy suggests repeated reduction of neuroarchitectural complexity in Annelida. Front Zool. 2010;7:21.

6. Purschke G, Bleidorn C, Struck TH. Systematics, evolution and phylogeny of Annelida - a morphological perspective. Mem Mus Vic. 2014:71:247-69.

7. Helm C, Bleidorn C. Annelida: Myzostomida. In: Schmidt-Rhaesa A, Harzsch S, Purschke G, editors. Structure and evolution of invertebrate nervous systems. 1st ed. Oxford: Oxford University Press; 2015. p. 241-7.

8. Kristof A, Maiorova AS. Annelida: Sipuncula. In: Schmidt-Rhaesa A Harzsch S, Purschke G, editors. Structure and evolution of invertebrate nervous systems. 1st ed. Oxford: Oxford University Press; 2015. p. 248-53.
9. Tomer R, Denes AS, Tessmar-Raible K, Arendt D. Profiling by image registration reveals common origin of annelid mushroom bodies and vertebrate pallium. Cell. 2010;142:800-9.

10. Heuer CM, Loesel R. Immunofluorescence analysis of the internal brain anatomy of Nereis diversicolor (Polychaeta, Annelida). Cell Tissue Res. 2007;331:713-24.

11. Helm C, Vöcking O, Kourtesis I, Hausen H. Owenia fusiformis-a basally branching annelid suitable for studying ancestral features of annelid neural development. BMC Evol Biol. 2016;16:1-19.

12. Rimskaya-Korsakova NN, Kristof A, Malakhov VV, Wanninger A. Neural architecture of Galathowenia oculata Zach, 1923 (Oweniidae, Annelida). Front Zool. 2016;13:5.

13. Worsaae K, Rouse GW. The simplicity of males: dwarf males of four species of Osedax (Siboglinidae; Annelida) investigated by confocal laser scanning microscopy. J Morphol. 2009;271:127-42.

14. Eichinger I, Hourdez S, Bright M. Morphology, microanatomy and sequence data of Sclerolinum contortum (Siboglindae, Annelida) of the Gulf of Mexico. Org Divers Evol. 2013;13:311-29.

15. Miyamoto N, Shinozaki A, Fujiwara Y. Neuroanatomy of the vestimentiferan tubeworm Lamellibrachia satsuma provides insights into the evolution of the polychaete nervous system. PLOS ONE. 2013;8:1-9.

16. Fröbius AC, Seaver EC. Capitella sp. I homeobrain-like, the first lophotrochozoan member of a novel paired-like homeobox gene family. Gene Exp Patterns. 2006:6:985-91.

17. HunnekuhI VS, Akam M. An anterior medial cell population with an apical-organ-like transcriptional profile that pioneers the central nervous system in the centipede Strigamia maritima. Dev Biol. 2014;396:136-49.

18. Tessmar-Raible K, Raible F, Christodoulou F, Guy K, Rembold M, Hausen $\mathrm{H}$, et al. Conserved sensory-neurosecretory cell types in annelid and fish forebrain: insights into hypothalamus evolution. Cell. 2007;129:1389-400.

19. Tessmar-Raible K, Steinmetz PRH, Snyman H, Hassel M, Arendt D. Fluorescent two-color whole mount in situ hybridization in Platynereis dumerilii (Polychaeta, Annelida), an emerging marine molecular model for evolution and development. Biotechniques. 2005;39:460-4.

20. Lartillot N, Le Gouar M, Adoutte A. Expression patterns of fork head and goosecoid homologues in the mollusc Patella vulgata supports the ancestry of the anterior mesendoderm across Bilateria. Dev Genes Evol. 2002;212:551-61.

21. Steinmetz PRH, Kostyuchenko RP, Fischer A, Arendt D. The segmental pattern of otx, gbx, and Hox genes in the annelid Platynereis dumerilii. Evol Dev. 2011;13:72-9.

22. Santagata S, Resh C, Hejnol A, Martindale MQ, Passamaneck YJ. Development of the larval anterior neurogenic domains of Terebratalia transversa (Brachiopoda) provides insights into the diversification of larval apical organs and the spiralian nervous system. Evodevo. 2012;3:1-21.

23. Marlow H, Tosches MA, Tomer R, Steinmetz PRH, Lauri A, Larsson T, et al. Larval body patterning and apical organs are conserved in animal evolution. BMC Biol. 2014;12:17.

24. Martin-Durán JM, Vellutini BC, Hejnol A. Evolution and development of the adelphophagic, intracapsular Schmidt's larva of the nemertean Lineus ruber. Evodevo. 2015:6:1-18.

25. Martin-Durán JM, Janssen R, Wennberg S, Budd GE, Hejnol A. Deuterostomic development in the protostome Priapulus caudatus. Curr Biol. 2012;22:2161-6.

26. Martin-Durán JM, Hejnol A. The study of Priapulus caudatus reveals conserved molecular patterning underlying different gut morphogenesis in the Ecdysozoa. BMC Biol. 2015;13:1-20.

27. Farris SM. Structural, functional and developmental convergence of the insect mushroom bodies with higher brain centers of vertebrates. Brain Behav Evol. 2008;72:1-15.

28. Reichert $\mathrm{H}$. Evolutionary conservation of mechanisms for neural regionalization, proliferation and interconnection in brain development. Biol Lett. 2008;5:112-6.

29. Lowe CJ, Wu M, Salic A, Evans L, Lander E, Stange-Thomann N, et al. Anteroposterior patterning in hemichordates and the origins of the chordate nervous system. Cell. 2003;113:853-65.

30. Aronowicz J, Lowe CJ. Hox gene expression in the hemichordate Saccoglossus kowalevskii and the evolution of deuterostome nervous systems. Integr Comp Biol. 2006;46:890-901. 
31. Amiel AR, Henry JQ, Seaver EC. An organizing activity is required for head patterning and cell fate specification in the polychaete annelid Capitella teleta: new insights into cell-cell signaling in Lophotrochozoa. Dev Biol. 2013;379:107-22.

32. Hui JHL, Raible F, Korchagina N, Dray N, Samain S, Magdelenat G, et al. Features of the ancestral bilaterian inferred from Platynereis dumerilii ParaHox genes. BMC Biol. 2009;7:43.

33. Meyer NP, Carrillo-Baltodano A, Moore RE, Seaver EC. Nervous system development in lecithotrophic larval and juvenile stages of the annelid Capitella teleta. Front Zool. 2015;12:15.

34. Steinmetz PRH, Urbach R, Posnien N, Eriksson J, Kostyuchenko RP, Brena $C$, et al. Six3 demarcates the anterior-most developing brain region in bilaterian animals. Evodevo. 2010;1:1-9.

35. Denes AS, Jekely G, Steinmetz PRH, Raible F, Snyman H, Prud'homme B, et al. Molecular architecture of annelid nerve cord supports common origin of nervous system centralization in bilateria. Cell. 2007;129:277-88.

36. Arenas-Mena C, Wong KS-Y. HeOtx expression in an indirectly developing polychaete correlates with gastrulation by invagination. Dev Genes Evol. 2007;217:373-84.

37. Arendt $D$, Technau U, Wittbrodt J. Evolution of the bilaterian larval foregut. Nature. 2001;409:81-5.

38. Boyle MJ, Yamaguchi E, Seaver EC. Molecular conservation of metazoan gut formation: evidence from expression of endomesoderm genes in Capitella teleta (Annelida). Evodevo. 2014;5:1-19.

39. Bruce AEE, Shankland M. Expression of the head gene Lox22-Otx in the Leech Helobdella and the origin of the bilaterian body plan. Dev Biol. 1998;201:101-12.

40. Grigoriev IV, Nordberg H, Shabalov I, Aerts A, Cantor M, Goodstein D, et al. The genome portal of the Department of Energy Joint Genoe Institute. Nucleic Acids Res. 2012;40:D26-32.

41. Bely $A E$, Wray GA. Evolution of regeneration and fission in annelids: insights from engrailed- and orthodenticle-class gene expression. Development. 2001;128:2781-91.

42. Arendt D, Tessmar K, Medeiros de Campos-Baptista M-I, Dorresteijn AW, Wittbrodt J. Development of pigment-cup eyes in the polychaete Platynereis dumerilii and evolutionary conservation of larval eyes in Bilateria. Development. 2002;129:1143-54.

43. Quigley IK, Xie X, Shankland M. Hau-Pax6A expression in the central nervous system of the leech embryo. Dev Genes Evol. 2007;217:459-68.

44. Conzelmann M, Williams EA, Tunaru S, Randel N, Shahidi R, Asadulina A, et al. Conserved MIP receptor-ligand pair regulates Platynereis larval settlement. PNAS. 2013;110:8224-9.

45. Saudemont A, Dray N, Hudry B, Le Gouar M, Vervoort M, Balavoine G. Complementary striped expression patterns of NK homeobox genes during segment formation in the annelid Platynereis. Dev Biol. 2008:317:430-43.

46. Meyer NP, Seaver EC. Neurogenesis in an annelid: characterization of brain neural precursors in the polychaete Capitella sp. I. Dev Biol. 2009;335:237-52.

47. Meyer NP, Seaver EC. Brain development in the annelid Capitella sp. I: insights into nervous system evolution. Dev Biol. 2009;331:463-4.

48. Quigley IK, Schmerer MW, Shankland M. A member of the Six gene family promotes the specification of $\mathrm{P}$ cell fates in the O/P equivalence group of the leech Helobdella. Dev Biol. 2010;344:319-30.

49. Müller MCM, Westheide W. Comparative analysis of the nervous systems in presumptive progenetic dinophilid and dorvilleid polychaetes (Annelida) by immunohistochemistry and CLSM. Acta Zool. 2002;83:33-48.

50. Fofanova EG, Nezlin LP, Voronezhskaya EE. Ciliary and nervous structures in juvenile females of the annelid Dinophilus gyrociliatus (O. Schmidt, 1948) (Annelida: Polychaeta). Russ J Mar Biol. 2014;40:43-52.

51. Jennings JB, Donworth PJ. Observations on the life cycle and nutrition of Dinophilus taeniatus Harmer 1889 (Annelida: Polychaeta). Ophelia. 1986;25:119-37.

52. Jägersten G. Zur Kenntnis der Morphologie, Enzystierung und Taxonomie von Dinophilus. Kungl Svenska Vetenskapsakad Handl. 1944;21:1-50.

53. Kerbl A, Bekkouche N, Sterrer W, Worsaae K. Detailed reconstruction of the nervous and muscular system of Lobatocerebridae with an evaluation of its annelid affinity. BMC Evol Biol. 2015;15:277.

54. Fofanova EG, Voronezhskaya EE. The structure of archiannelid Dinophilus gyrociliatus ventral nerve cords. Acta Biol Hung. 2012;63:88-90.
55. Worsaae K, Rimskaya-Korsakova NN, Rouse GW. Neural reconstruction of bone-eating Osedax spp. (Annelida) and evolution of the siboglinid nervous system. BMC Evol Biol. 2016;16:1-23.

56. Hejnol A, Lowe CJ. Embracing the comparative approach: how robust phylogenies and broader developmental sampling impacts the understanding of nervous system evolution. Philos Trans R Soc Biol. 2015;370:20150045.

57. Holland LZ, Carvalho JE, Escriva H, Laudet V, Schubert M, Shimeld SM, et al. Evolution of bilaterian central nervous systems: a single origin? Evodevo. 2013;4:27.

58. Ax P. Das Fortpflanzungsverhalten von Trilobodrilus (Archiannelida, Dinophilidae). Mar Biol. 1968;1:330-5.

59. Donworth PJ. A reappraisal and validation of the species Dinophilus taeniatus Harmer 1889 and of taxonomically significant features in monomorphic dinophilids (Annelida: Polychaeta). Zool Anz. 1985;216:32-8.

60. Riser NW. Description of a new species of dinophilid polychaete, with observations on other dinophilids and interstitial polychaetes in New England. North East Nat. 1999;6:211-20.

61. Westheide W. The systematic position of the Dinophilidae and the archiannelid problem. In: Conway Morris S, George JD, Gibson R, Platt $\mathrm{HM}$, editors. The origins and relationships of lower invertebrates. Oxford: Systematic Association; 1985. p. 310-26.

62. Nelson JA. The early development of Dinophilus: a study in cell-lineage. Proc Acad Natl Sci Philos. 1904;56:687-737.

63. Harmer SF. Notes on the anatomy of Dinophilus. Proc Camb Philos Soc. 1889;6:119-43.

64. Jägersten G. Life cycle of Dinophilus, with special reference to the encystment and its dependence on temperature. Oikos. 1951;3:143-65.

65. Korschelt E. Die Gattung Dinophilus und der bei ihr auftretende Geschlechtsdimorphismus. Zool Jahrb Abt allg Zool Physiol Tiere. 1887;2:955-67.

66. Jennings JB, Gelder SR. Feeding and digestion in Dinophilus gyrociliatus (Annelida: Archiannelida). J Zool (London). 1969;158:441-51.

67. Windoffer R, Westheide W. The nervous system of the male Dinophilus gyrociliatus (Annelida: Polychaeta). I. Number, types and distribution pattern of sensory cells. Acta Zool. 1988;69:55-64.

68. Windoffer R, Westheide W. The nervous system of the male Dinophilus gyrociliatus (Polychaeta, Dinophilidae): II. Electron microscopical reconstruction of nervous anatomy and effector cells. J Comp Neurol. 1988;272:475-88.

69. Åkesson B, Costlow JD. Effects of constant and cyclic temperatures at different salinity levels on survival and reproduction in Dinophilus gyrociliatus (Polychaeta: Dinophilidae). Bull Mar Sci. 1991;48:485-99.

70. Haas BJ, Papanicolaou A, Yassour M, Grabherr M, Blood PD, Bowden J, et al. De novo transcript sequence reconstruction from RNA-seq using the Trinity platform for reference generation and analysis. Nat Protoc. 2013:8:1494-512.

71. Edgar RC. MUSCLE: a multiple sequence alignment method with reduced time and space complexity. BMC Bioinform. 2004;5:1-19.

72. Ronquist F, Huelsenbeck JP. MrBayes 3: Bayesian phylogenetic inference under mixed models. Bioinformatics. 2003;19:1572-4.

73. Hejnol A. In situ-protocol for embryos and juveniles of Convolutriloba longifissura. Protoc Exch. 2008. doi:10.1038/nprot.2008.201.

74. Hewes RS. The bHLH protein Dimmed controls neuroendocrine cell differentiation in Drosophila. Development. 2003;130:1771-81.

75. Park D, Shafer OT, Shepherd SP, Suh H, Trigg JS, Taghert PH. The Drosophila basic helix-loop-helix protein DIMMED directly activates PHM, a gene encoding a neuropeptide-amidating enzyme. Mol Cell Biol. 2008:28:410-21.

76. Gauthier SA, Hewes RS. Transcriptional regulation of neuropeptide and peptide hormone expression by the Drosophila dimmed and cryptocephal genes. J Exp Biol. 2006;209:1803-15.

77. Blackburn DC, Conley KW, Plachetzki DC, Kempler K, Battelle B-A, Brown $\mathrm{NL}$. Isolation and expression of Pax6 and atonal homologues in the American horseshoe crab, Limulus polyphemus. Dev Dyn. 2008;237:2209-19.

78. Oliver G, Mailhos A, Wehr R, Copeland NG, Jenkins NA, Gruss P. Six3, a murine homologue of the sine oculis gene, demarcates the most anterior border of the developing neural plate and is expressed during eye development. Development. 1995;121:4025-55. 
79. Conzelmann M, Jekely G. Antibodies against conserved amidated neuropeptide epitopes enrich the comparative neurobiology toolbox. Evodevo. 2012;3:1-12

80. Fröbius AC, Seaver EC. ParaHox gene expression in the polychaete annelid Capitella sp. I. Dev Genes Evol. 2006;216:81-8.

81. Kang D, Huang F, Li D, Shankland M, Gaffield W, Weisblat DA. A hedgehog homolog regulates gut formation in leech (Helobdella). Development. 2003;130:1645-57.
82. Holland LZ. Body-plan evolution in the Bilateria: early antero-posterior patterning and the deuterostome-protostome dichotomy. Curr Opin Genet Dev. 2000;10:434-42.

83. Farris SM. Evolutionary convergence of higher brain centers spanning the protostome-deuterostome boundary. Brain Behav Evol. 2008;72:106-22.

84. Hirth F. An urbilaterian origin of the tripartite brain: developmental genetic insights from Drosophila. Development. 2003;130:2365-73.

\section{Submit your next manuscript to BioMed Central} and we will help you at every step:

- We accept pre-submission inquiries

- Our selector tool helps you to find the most relevant journal

- We provide round the clock customer support

- Convenient online submission

- Thorough peer review

- Inclusion in PubMed and all major indexing services

- Maximum visibility for your research

Submit your manuscript at www.biomedcentral com/submit 